\title{
Automatic Stabilizers and Economic Crisis: US vs. Europe
}

\author{
Mathias Dolls*, Clemens Fuest ${ }^{\ddagger}$, Andreas Peichl ${ }^{\S}$ \\ This version: January 27, 2010
}

\begin{abstract}
This paper analyzes the effectiveness of the tax and transfer systems in the European Union and the US to act as an automatic stabilizer in the current economic crisis. We find that automatic stabilizers absorb 38 per cent of a proportional income shock in the EU, compared to 32 per cent in the US. In the case of an unemployment shock 48 per cent of the shock are absorbed in the EU, compared to 34 per cent in the US. This cushioning of disposable income leads to a demand stabilization of 26 to 35 per cent in the EU and 19 per cent in the US. There is large heterogeneity within the EU. Automatic stabilizers in Eastern and Southern Europe are much lower than in Central and Northern European countries. We also investigate whether countries with weak automatic stabilizers have enacted larger fiscal stimulus programs. We find no evidence supporting this view. However, we find that active fiscal policy is lower in more open economies.
\end{abstract}

*CGS - University of Cologne and IZA, dolls@wiso.uni-koeln.de

${ }^{\ddagger}$ University of Oxford (Centre for Business Taxation), University of Cologne, CESifo and IZA, clemens.fuest@sbs.ox.ac.uk

${ }_{\S}^{\S}$ IZA Bonn, University of Cologne and ISER, peichl@iza.org

T This paper uses EUROMOD version D21 and TAXSIM v9. EUROMOD and TAXSIM are continually being improved and updated and the results presented here represent the best available at the time of writing. Our version of TAXSIM is based on the Survey of Consumer Finances (SCF) by the Federal Reserve Board. EUROMOD relies on micro-data from 17 different sources for 19 countries. These are the ECHP and EU-SILC by Eurostat, the Austrian version of the ECHP by Statistik Austria; the PSBH by the University of Liège and the University of Antwerp; the Estonian HBS by Statistics Estonia; the Income Distribution Survey by Statistics Finland; the EBF by INSEE; the GSOEP by DIW Berlin; the Greek HBS by the National Statistical Service of Greece; the Living in Ireland Survey by the Economic and Social Research Institute; the SHIW by the Bank of Italy; the PSELL-2 by CEPS/INSTEAD; the SEP by Statistics Netherlands; the Polish HBS by Warsaw University; the Slovenian HBS and Personal Income Tax database by the Statistical Office of Slovenia; the Income Distribution Survey by Statistics Sweden; and the FES by the UK Office for National Statistics (ONS) through the Data Archive. Material from the FES is Crown Copyright and is used by permission. Neither the ONS nor the Data Archive bears any responsibility for the analysis or interpretation of the data reported here. An equivalent disclaimer applies for all other data sources and their respective providers.

This paper is partly based on work carried out during Andreas Peichl's visit to the European Centre for Analysis in the Social Sciences (ECASS) at the Institute for Social and Economic Research (ISER), University of Essex, supported by the Access to Research Infrastructures action under the EU Improving Human Potential Programme. Andreas Peichl is grateful for financial support by Deutsche Forschungsgemeinschaft DFG (PE1675). We would like to thank Danny Blanchflower, Dean Baker, Horacio Levy, Torfinn Harding, participants of the 2009 IZA/CEPR ESSLE and IZA Prize conferences and the 6th German-Norwegian Seminar on Public Economics (CESifo) as well as seminar participants in Bonn, Cologne, Nuremberg, Siegen and at the Worldbank for helpful comments and suggestions. We are grateful to Daniel Feenberg for granting us access to TAXSIM and helping us with our simulations. We are indebted to all past and current members of the EUROMOD consortium for the construction and development of EUROMOD. The usual disclaimer applies. 
JEL Codes: E32, E63, H2, H31

Keywords: Automatic Stabilization, Crisis, Liquidity Constraints, Fiscal Stimulus 


\section{Introduction}

In the current economic crisis, the workings of automatic stabilizers are widely seen to play a key role in stabilizing demand and output. Automatic stabilizers are usually defined as those elements of fiscal policy which mitigate output fluctuations without discretionary government action (see, e.g., Eaton and Rosen (1980)). Despite the importance of automatic stabilizers for stabilizing the economy, "very little work has been done on automatic stabilization [...] in the last 20 years" (Blanchard (2006)). However, especially in the current crisis, it is important to assess the contribution of automatic stabilizers to overall fiscal expansion and to compare their magnitude across countries. Previous research on automatic stabilization has mainly relied on macro data. Exceptions based on micro data are Auerbach and Feenberg (2000) for the US and Mabbett and Schelkle (2007) for the EU-15. Much more comparative work based on micro data has been conducted on the differences in the tax wedge and effective marginal tax rates between the US and European countries (see, e.g., Piketty and Saez (2007)).

In this paper, we combine these two strands of the literature to compare the magnitude and composition of automatic stabilization between the US and Europe based on micro data estimates. We analyze the impact of automatic stabilizers using microsimulation models for 19 European countries (EUROMOD) and the US (TAXSIM). The microsimulation approach allows us to investigate the causal effects of different types of shocks on household disposable income, holding everything else constant and therefore avoiding endogeneity problems (see Bourguignon and Spadaro (2006)). We can hence single out the role of automatic stabilization which is not possible in an ex-post evaluation (or with macro data) as it is not possible to disentangle the effects of automatic stabilizers, active fiscal and monetary policy and behavioral responses like changes in labor supply or disability benefit take-up.

We run two controlled experiments of macro shocks to income and employment. The first is a proportional decline in household gross income by $5 \%$ (income shock). This is the usual way of modeling shocks in simulation studies analyzing automatic stabilizers. However, economic downturns typically affect households asymmetrically, with some households losing their jobs and suffering a sharp decline in income and other households being much less affected, as wages are usually rigid in the short term. We therefore consider a second macro shock where some households become unemployed, so that the unemployment rate increases by five percentage 
points (unemployment shock). We show that these two types of shocks and the resulting stabilization coefficients can be interpreted as an average effective marginal tax rate (EMTR) for the whole tax benefit system at the intensive (proportional income shock) or extensive (unemployment shock) margin. After identifying the effects of these shocks on disposable income, we use methods developed by Zeldes (1989) to estimate the prevalence of credit constraints among households. On this basis, we calculate how the stabilization of disposable income can translate into demand stabilization.

As our measure of automatic stabilization, we extend the normalized tax change (Auerbach and Feenberg (2000)) to include other taxes as well as social contributions and benefits. Our income stabilization coefficient relates the shock absorption of the whole tax and transfer system to the overall size of the income shock. We take into account personal income taxes (at all government levels), social insurance contributions and payroll taxes paid by employers and employees, value added or sales taxes as well as transfers to private households like, e.g., unemployment benefits. ${ }^{1}$ Computations are done according to the tax benefit rules which were in force before 2008 in order to avoid an endogeneity problem resulting from any policy responses after the start of the crisis.

What does the present paper contribute to the literature? First, previous studies have focused on proportional income shocks whereas our analysis shows that automatic stabilizers work very differently in the case of unemployment shocks, which affect households asymmetrically. ${ }^{2}$ This is especially important for assessing the effectiveness of automatic stabilizers in the current economic crisis. Second, we extend the micro data measure on automatic stabilization to different taxes and benefits. Our analysis includes a decomposition of the overall stabilization effects into the contributions of taxes, social insurance contributions and benefits. A further difference between our study and Auerbach and Feenberg (2000) is that we take into account unemployment benefits and state level income taxes as well as consumption taxes. This explains why our estimates of overall automatic stabilization effects in the US are higher. Third, to the best of our knowledge, our study is the first to

\footnotetext{
${ }^{1}$ We abstract from other taxes, in particular corporate income taxes. For an analysis of automatic stabilizers in the corporate tax system see Devereux and Fuest (forthcoming) and Buettner and Fuest (2009).

${ }^{2}$ Auerbach and Feenberg (2000) do consider a shock where households at different income levels are affected differently, but the results are very similar to the case of a symmetric shock. Our analysis confirms this for the US, but not for Europe.
} 
estimate the prevalence of liquidity constraints for EU household data. ${ }^{3}$ This is of key importance for assessing the role of automatic stabilizers for demand smoothing. Fourth, we extend the analysis to more recent years and countries - including transition countries from Eastern Europe - and we compare the US and Europe within the same microeconometric framework. Finally, we shed light on the issue whether macro indicators are a good proxy for micro data based stabilization coefficients. We also investigate whether bigger governments or more open economies lead to higher / lower automatic stabilizers.

We show that our extensions to previous research are important for the comparison between the U.S. and Europe as they help to identify driving forces in automatic stabilization. Our analysis leads to the following main results. In the case of an income shock, approximately $38 \%$ of the shock would be absorbed by automatic stabilizers in the EU. For the US, we find a value of $32 \%$. This is surprising because automatic stabilizers in Europe are usually perceived to be drastically higher than in the US. Our results qualify this view to some extent, at least as far as proportional shocks on household income are concerned. When looking at the personal income tax only, the values for the US are even higher than the EU average. Within the EU, there is considerable heterogeneity, and results for overall stabilization of disposable income range from a value of $25 \%$ for Estonia to $56 \%$ for Denmark. In general automatic stabilizers in Eastern and Southern European countries are considerably lower than in Continental and Northern European countries. In the case of the unemployment shock, the difference between the EU and the US is larger. EU automatic stabilizers absorb $48 \%$ of the shock whereas the stabilization effect in the US is only $34 \%$. Again, there is considerable heterogeneity within the EU.

How does this cushioning of shocks translate into demand stabilization? Since demand stabilization can only be achieved for liquidity constrained households, the picture changes significantly. For the income shock, the cushioning effect of automatic stabilizers is now equal to $26 \%$ in the EU. For the US, we find a value of $19 \%$, which is again rather similar. For the unemployment shock, however, we find a large difference. In the EU, the stabilization effect is equal to $35 \%$ whereas the value for the US (19\%) is similar to the value for the income shock. These results suggest that social transfers, in particular the rather generous systems of unemploy-

\footnotetext{
${ }^{3}$ There are several studies on liquidity constraints and the responsiveness of households to tax changes for the US (see, e.g., Zeldes (1989), Parker (1999), Souleles (1999), Johnson et al. (2006), Shapiro and Slemrod $(1995,2003,2009))$
} 
ment insurance in Europe, play a key role for demand stabilization and explain an important part of the difference in automatic stabilizers between Europe and the US.

A final issue we discuss in the paper is how fiscal stimulus programs of individual countries are related to automatic stabilizers. In particular, we ask whether countries with low automatic stabilizers have tried to compensate this by larger fiscal stimuli, but we find no correlation between the size of fiscal stimulus programs and automatic stabilizers. However, we find that active fiscal policy is lower in more open economies.

The paper is structured as follows. In Section 2 we provide a short overview on previous research with respect to automatic stabilization and comparisons of US and European tax benefit systems. In addition, we discuss how stabilization effects can be measured. Section 3 describes the microsimulation models EUROMOD and TAXSIM and the different macro shock scenarios we consider. Section 4 presents the results on automatic stabilization which are discussed in Section 5 together with potential limitations of our approach. In Section 6, we shortly discuss distributional implications of the analyzed macro shock scenarios. Section 7 concludes.

\section{Previous research and theoretical framework}

\subsection{Previous research}

There are two strands of literature which are related to our paper. First, in the literature on the analysis and measurement of automatic fiscal stabilizers, scholars have estimated automatic stabilizers mostly based on macro data. Related to this literature are studies which have investigated the relationship between openness, output volatility and government size, a proxy for automatic fiscal stabilizer. Second, there is a growing literature on international comparisons of income tax systems. This literature has mainly relied on micro data and the simulation approach in order to take into account the heterogeneity of the population.

In the empirical literature on automatic stabilizers ${ }^{4}$, two types of studies prevail: macro data studies and micro data estimates. ${ }^{5}$ The common baseline of macro data

\footnotetext{
${ }^{4} \mathrm{~A}$ theoretical analysis of automatic stabilizers in a real business cycle model can be found in Galí (1994).

${ }^{5}$ Early estimates on the responsiveness of the tax system to income fluctuations are discussed in the Appendix of Goode (1976). More recent contributions include Fatàs and Mihov (2001),
} 
studies is to measure the cyclical elasticitiy of different budget components such as the income tax, social security contributions, the corporate tax, indirect taxes or unemployment benefits. Different approaches have been proposed, for example regressing changes in fiscal variables on the growth rate of GDP or estimating elasticities on the basis of macro-econometric models. ${ }^{6}$ Sachs and Sala-i Martin (1992) and Bayoumi and Masson (1995) use time series data and find values of 30\%-40\% for disposable income stabilization in the US. However, these approaches face several drawbacks from which the most serious one is probably the impossibility of separating discretionary actions from automatic stabilizers in combination with identification problems resulting from endogenous regressors. Related to the literature on macro estimations of automatic stabilization are studies that focus on the relationship between output volatility, public sector size and openness of the economy (Cameron (1978), Galí (1994), Rodrik (1998), Fatàs and Mihov (2001), Auerbach and Hassett (2002)).

Much less work has been done on the exact identification of automatic stabilizers resulting from tax and transfer systems with micro data. Auerbach and Feenberg (2000) use the NBER's microsimulation model TAXSIM to estimate the automatic stabilization for the US from 1962-95 and find values for the stabilization of disposable income ranging between 25\%-35\%. Auerbach (2009) has updated this analysis and finds a value around $25 \%$ for more recent years. Mabbett and Schelkle (2007) conduct a similar analysis for 15 Western European countries in 1998 and find higher stabilization effects than in the US, with results ranging from $32 \%-58 \%{ }^{7}$ How does this smoothing of disposable income affect household demand? To the best of our knowledge, Auerbach and Feenberg (2000) is the only simulation study which tries to estimate the demand effect taking into account liquidity constraints. They use the method suggested by Zeldes (1989) and find that approximately two thirds of all households are likely to be liquidity constrained. Given this, the contribution of automatic stabilizers to demand smoothing is reduced to approximately $15 \%$ of the initial income shock.

The second strand this paper adds to is the literature on international compar-

Blanchard and Perotti (2002), Mélitz and Zumer (2002).

${ }^{6}$ Cf. van den Noord (2000) or Girouard and André (2005).

${ }^{7}$ Mabbett and Schelkle (2007) rely for their analysis (which is a more recent version of Mabbett (2004)) on the results from an inflation scenario taken from Immvervoll et al. (2006) who use the microsimulation model EUROMOD to increase earnings by $10 \%$ in order to simulate the sensitivity of poverty indicators with respect to macro level changes. 
isons of income tax systems in terms of effective average and marginal tax rates, and individual tax wedges between the US and European countries. Here, micro data allow much more detailed analyses which are not possible with macro data. Piketty and Saez (2007) use large public micro-file tax return data for the US to compute average tax rates for five federal taxes and different income groups and complement the analysis for the US with a comparison to France and the UK. A key finding from their analysis is that today (and in contrast to 1970), France as a continental European welfare state has higher average tax rates compared with the two Anglo-Saxon countries and its tax system possesses a higher degree of progressivity. Immvervoll (2004) discusses conceptual issues with regard to macro- and micro-based measures of the tax burden and compares effective tax rates in fourteen EU Member States. In general, he finds a large heterogeneity across countries with average and marginal effective tax rates lowest in southern European countries. Other studies take as given that European tax systems reveal a higher degree of progressivity (e.g. Alesina and Glaeser (2004)) or higher (marginal) tax rates in general (e.g. Prescott (2004) or Alesina et al. (2005)) and discuss if and to what extent differences in economic outcomes such as hours worked can be explained by different tax structures. This paper providing new measures of the average effective marginal tax rate (EMTR) both at the intensive and extensive margin for the US and 19 European countries shall help to shed further light on existing differences between the US and European tax and transfer systems.

\subsection{Theoretical framework}

The extent to which automatic stabilizers mitigate the impact of income shocks on household demand essentially depends on two factors. Firstly, the tax and transfer system determines the way in which a given shock to gross income translates into a change in disposable income. For instance, in the presence of a proportional income tax with a tax rate of $40 \%$, a shock on gross income of one hundred Euros leads to a decline in disposable income of 60 Euros. In this case, the tax absorbs $40 \%$ of the shock to gross income. A progressive tax, in turn, would have a stronger stabilizing effect. Secondly, the link between current disposable income and current demand for goods and services is crucial. If the income shock is perceived as transitory and current demand depends on some concept of permanent income, and if households can borrow, their demand will not change. In this case, the impact of automatic 
stabilizers on current demand would be equal to zero. Things are different, though, if households are liquidity constrained. In this case, their current expenditures do depend on disposable income so that automatic stabilizers play a role.

A common measure for estimating automatic stabilization is the "normalized tax change" used by Auerbach and Feenberg (2000) which can be interpreted as "the tax system's built-in flexibility" (Pechman $(1973,1987)$ ). It shows how changes in market income translate into changes in disposable income through changes in personal income tax payments.

Market income $Y_{i}^{M}$ of individual $i$ is defined as the sum of all incomes from market activities:

$$
Y_{i}^{M}=E_{i}+Q_{i}+I_{i}+P_{i}+O_{i}
$$

where $E_{i}$ are earnings, $Q_{i}$ business income, $I_{i}$ capital income, $P_{i}$ property income, and $O_{i}$ other income. Disposable income $Y_{i}^{D}$ is defined as market income minus net government intervention $G_{i}=T_{i}+S_{i}-B_{i}$ :

$$
Y_{i}^{D}=Y_{i}^{M}-G_{i}=Y_{i}^{M}-\left(T_{i}+S_{i}-B_{i}\right)
$$

where $T_{i}$ are direct taxes, $S_{i}$ employee social insurance contributions, and $B_{i}$ are social cash benefits (i.e. negative taxes). Note that an extended analysis including employer social insurance contributions and consumption taxes is presented in Section 4.3.

We extend the "normalized tax change" to include other taxes as well as social insurance contributions and benefits. This allows us to relate the shock absorption by the whole tax and transfer system to the overall size of the income shock. We take into account personal income taxes (at all government levels), social insurance contributions as well as payroll taxes and transfers to private households like, e.g., unemployment benefits. In the following, we simply refer to our measure as the income stabilization coefficient $\tau^{I}$. We derive $\tau^{I}$ from a general functional relationship between disposable income and market income:

$$
\tau^{I}=\tau^{I}\left(Y^{M}, T, S, B\right)
$$

The derivation can be either done on the macro or on the micro level. On the macro level, it holds that the aggregate change in market income $\left(\Delta Y^{M}\right)$ is 
transmitted via $\tau^{I}$ into an aggregate change in disposable income $\left(\Delta Y^{D}\right)$ :

$$
\Delta Y^{D}=(1-\tau) \Delta Y^{M}
$$

It can be easily shown that $\tau^{I}$ stabilizes GDP:

$$
\begin{aligned}
G D P & =C+I+G+N X \\
\Delta G D P & =\Delta C+\Delta I+\Delta G+\Delta N X \\
\Delta G D P & =(1-\tau) \Delta Y^{M}+\Delta G+\Delta N X
\end{aligned}
$$

with $C$ private consumption, $I=S$ private investments (savings), $G$ government activity and $N X$ net exports, and $Y^{D}=C+S$.

However, one problem when comupting $\tau^{I}$ with macro data is that this data includes behavioral and general equilibrium effects as well as active policy. Therefore, a measure of automatic stabilization based on macro data captures all these effects. In order to single out the pure size of automatic stabilization, we compute $\tau^{I}$ using arithmetic changes $(\Delta)$ in total disposable income $\left(\sum_{i} \Delta Y_{i}^{D}\right)$ and market income $\left(\sum_{i} \Delta Y_{i}^{M}\right)$ based on micro level information:

$$
\begin{aligned}
\sum_{i} \Delta Y_{i}^{D} & =\left(1-\tau^{I}\right) \sum_{i} \Delta Y_{i}^{M} \\
\tau^{I} & =1-\frac{\sum_{i} \Delta Y_{i}^{D}}{\sum_{i} \Delta Y_{i}^{M}}=\frac{\sum_{i}\left(\Delta Y_{i}^{M}-\Delta Y_{i}^{D}\right)}{\sum_{i} \Delta Y_{i}^{M}}=\frac{\sum_{i} \Delta G_{i}}{\sum_{i} \Delta Y_{i}^{M}}
\end{aligned}
$$

$\tau^{I}$ measures the sensitivity of disposable income, $Y_{i}^{D}$, with respect to market income, $Y_{i}^{M}$. The higher $\tau^{I}$, the stronger the stabilization effect, e.g. $\tau^{I}=0.4 \mathrm{im}$ plies that $40 \%$ of the income shock is absorbed by the tax benefit system. Note that the income stabilization coefficient is not only determined by the size of government (e.g. measured as expenditure or revenue in percent of GDP) but also depends on the structure of the tax benefit system and the design of the different components.

Note that the definition of $\tau^{I}$ resembles that of an average effective marginal tax rate (EMTR), which is usually computed in this way using micro data (Immvervoll (2004)). In the case of the proportional income shock, $\tau^{I}$ can be interpreted as the EMTR along the intensive margin, whereas in the case of the unemployment shock, 
it resembles the EMTR along the extensive margin (participation tax rate, see, e.g., Saez (2001, 2002), Kleven and Kreiner (2006) or Immervoll et al. (2007)).

Furthermore, it is important to explore the extent to which different individual components of the tax transfer system contribute to stabilization. Comparing tax benefit systems in Europe and the US, we are interested in the weight of each component in the respective country. We therefore decompose the coefficient into its components which include taxes, social insurance contributions and benefits:

$\tau^{I}=\sum_{f} \tau_{f}^{I}=\tau_{T}^{I}+\tau_{S}^{I}+\tau_{B}^{I}=\frac{\sum_{i} \Delta T_{i}}{\sum_{i} \Delta Y_{i}^{M}}+\frac{\sum_{i} \Delta S_{i}}{\sum_{i} \Delta Y_{i}^{M}}-\frac{\sum_{i} \Delta B_{i}}{\sum_{i} \Delta Y_{i}^{M}}=\frac{\sum_{i}\left(\Delta T_{i}+\Delta S_{i}-\Delta B_{i}\right)}{\sum_{i} \Delta Y_{i}^{M}}$

However, in order to stabilize final demand and output, the cushioning effect on disposable income has to be transmitted to expenditures for goods and services. If current demand depends on some concept of permanent income, demand will not change in response to a transitory income shock. Things are different, though, if households are liquidity constrained and cannot borrow. In this case, their current expenditures do depend on disposable income so that automatic stabilizers play a role. Following Auerbach and Feenberg (2000), we assume that households who face liquidity constraints fully adjust consumption expenditure after changes in disposable income while no such behavior occurs among households without liquidity constraints. $^{8}$ The adjustment of liquidity constrained households takes place such that changes in disposable income are equal to changes in consumption. Hence, the coefficient which measures stabilization of aggregate demand becomes:

$$
\tau^{C}=1-\frac{\sum_{i} \Delta C_{i}^{L Q}}{\sum_{i} \Delta Y_{i}^{M}}
$$

where $\Delta C_{i}^{L Q}$ denotes the consumption response of liquidity constrained households. In the following, we refer to $\tau^{C}$ as the demand stabilization coefficient. In order to explore the sensitivity of our estimates of the demand stabilization coefficient with respect to the way in which liquidity constrained households are identified, we choose two different approaches. In the first one, we use the same approach as

\footnotetext{
${ }^{8}$ Note that the term "liquidity constraint" does not have to be interpreted in an absolute inability to borrow but can also come in a milder form of a substantial difference between borrowing and lending rates which can result in distortions of the timing of purchases. Note further that our demand stabilization coefficient does not predict the overall change of final demand, but the extent to which demand is stabilized by the tax benefit system.
} 
Auerbach and Feenberg (2000) and follow Zeldes (1989) to split the samples according to a specific wealth to income ratio. A household is liquidity constrained if its capitalized wealth $W_{i}$ is less than the disposable income of at least two months, i.e:

$$
L Q_{i}=\mathbf{1}\left[W_{i} \leq \frac{2}{12} Y_{i}^{D}\right]
$$

The second approach simply considers the bottom $75 \%$ of the gross income distribution to be liquidity constrained.

\subsection{Extension}

In this section, we include employer social insurance contribution and consumption taxes in our analysis. The inclusion of employer social insurance contributions is of interest for two reasons. First, in our basic analysis, gross income is identical to market income by definition. This does not hold, however, if employer social insurance contributions are included. In this case, gross income is defined as follows:

$$
Y_{i}^{G}=Y_{i}^{M}+S_{i}^{E R}
$$

where $Y_{i}^{G}$ is gross income, $Y_{i}^{M}$ market income and $S_{i}^{E R}$ employer social insurance contributions. The fact that gross income is larger than market income when employer SIC are included explains why stabilization results may not only differ for SIC, but also for taxes and benefits. Second, legislation with respect to the financing of social insurance can be very different across countries. ${ }^{9}$ Contributions are not shared equally between employers and employees in all countries as it is the case, e.g., in the US or Germany.

The income stabilization coefficient can now be decomposed as follows:

$$
\tau^{I}=\sum_{f} \tau_{f}^{I}=\frac{\sum_{i}\left(\Delta T_{i}+\Delta S_{i}-\Delta B_{i}+\Delta C T_{i}\right)}{\sum_{i} \Delta Y_{i}^{M}}
$$

where $\Delta S_{i}$ includes the change in both employer and employee social insurance contributions and $\triangle C T_{i}$ is the difference in consumption tax payments given that all disposable income is consumed. In our computations, we use the implicit tax

\footnotetext{
${ }^{9}$ E.g. Ankrom (1993) also follows this approach. He argues that ignoring employers' social contributions would implicitly assume that the wage elasticity of labour supply is infinite. However, empirical analyses rather suggest the opposite and therefore this can significantly bias the results of the effectiveness of tax and transfer systems.
} 
rate (ITR) on consumption taken from European Commission (2009b) for European countries and McIntyre et al. (2003) for the US, which is a measure for the effective tax burden as it includes several consumption taxes such as VAT, energy and other excise taxes. ${ }^{10}$

\section{Data and methodology}

\subsection{Microsimulation using TAXSIM and EUROMOD}

We use microsimulation techniques to simulate taxes, benefits and disposable income under different scenarios for a representative micro-data sample of households. Simulation analysis allows conducting a controlled experiment by changing the parameters of interest while holding everything else constant (cf. Bourguignon and Spadaro (2006)). We therefore do not have to deal with endogeneity problems when identifying the effects of the policy reform under consideration.

Simulations are carried out using TAXSIM - the NBER's microsimulation model for calculating liabilities under US Federal and State income tax laws from individual data - and EUROMOD, a static tax-benefit model for 19 EU countries, which was designed for comparative analysis. ${ }^{11}$ The models can simulate most direct taxes and benefits except those based on previous contributions as this information is usually not available from the cross-sectional survey data used as input datasets. Information on these instruments is taken directly from the original data sources. Both models assume full benefit take-up and tax compliance, focusing on the intended effects of tax-benefit systems. The main stages of the simulations are the following. First, a micro-data sample and tax-benefit rules are read into the model. Then for each tax and benefit instrument, the model constructs corresponding assessment

\footnotetext{
${ }^{10}$ Note that this approach implicitly assumes that the marginal savings rate remains unchanged before and after the shock. This does not have to be the case as some households might have to decrease their savings due to decreasing disposable income, whereas others might even increase it (precautionary savings).

${ }^{11}$ For more information on TAXSIM see Feenberg and Coutts (1993) or visit http://www.nber.org/taxsim/. For further information on EUROMOD see Sutherland (2001, 2007). There are also country reports available with detailed information on the input data, the modeling and validation of each tax benefit system, see http://www.iser.essex.ac.uk/research/euromod. The tax-benefit systems included in the model have been validated against aggregated administrative statistics as well as national tax-benefit models (where available), and the robustness checked through numerous applications (see, e.g., Bargain (2006)).
} 
units, ascertains which are eligible for that instrument and determines the amount of benefit or tax liability for each member of the unit. Finally, after all taxes and benefits in question are simulated, disposable income is calculated.

\subsection{Scenarios}

The existing literature on stabilization so far has concentrated on increases in earnings or gross incomes to examine the stabilizing impact of tax benefit systems. In the light of the current economic crisis, there is much more interest in a downturn scenario. Reinhart and Rogoff (2009) stress that recessions which follow a financial crisis have particularly severe effects on asset prices, output and unemployment. Therefore, we are interested not only in a scenario of a uniform decrease in incomes but also in an increase of the unemployment rate. We compare a scenario where gross incomes are decreased by $5 \%$ (income shock) to a scenario where the unemployment rate increases by five percentage points (unemployment shock). ${ }^{12}$

The increase of the unemployment rate is modeled through reweighting of our samples. ${ }^{13}$ The weights of the unemployed are increased while those of the employed with similar characteristics are decreased, i.e., in effect, a fraction of employed households is made unemployed. With this reweighting approach we control for several individual and household characteristics that determine the risk of becoming unemployed (see Appendix A.2). The implicit assumption behind this approach is that the socio-demographic characteristics of the unemployed remain constant. ${ }^{14}$

\footnotetext{
${ }^{12}$ Our scenarios can be seen as a conservative estimate of the expected impact of the current crisis (see Reinhart and Rogoff (2009) for effects of previous crises). The (qualitative) results are robust with respect to different sizes of the shocks. It would be further possible to derive more complicated scenarios with different shocks on different income sources or a combination of income and unemployment shock. However, this would only have an impact on the distribution of changes which are not relevant in the analysis of this paper. Therefore, we focus on these two simple scenarios in order to make our analysis as simple as possible. One should note, though, that our analysis is not a forecasting exercise. We do not aim at quantifying the exact effects of the current economic crisis but of stylized scenarios in order to explore the build-in automatic stabilizers of existing pre-crisis tax-benefit systems. Conducting an ex-post analysis would include discretionary government reactions and behavioral responses (see, e.g., Aaberge et al. (2000) for an empirical ex-post analysis of a previous crisis in the Nordic countries) and we would not be able to identify the role of automatic stabilization.

${ }^{13}$ For the reweigthing procedure, we follow the approach of Immvervoll et al. (2006), who have also simulated an increase in unemployment through reweighting of the sample. Their analysis focuses on changes in absolute and relative poverty rates after changes in the income distribution and the employment rate.

${ }^{14}$ Cf. Deville and Särndal (1992) and DiNardo et al. (1996). This approach is equivalent to estimating probabilities of becoming unemployed (see, e.g., Bell and Blanchflower (2009)) and then
} 


\section{Results}

\subsection{US vs. Europe}

We start our analysis by comparing the US to Europe. Our simulation model includes 19 European countries which we treat as one single country (i.e. the "United States of Europe"). All of them are EU member states, which is why we refer to this group as the EU, bearing in mind that some EU member countries are missing. We also consider the countries of the Euro area and refer to this group as 'Euro'. Figure 1 summarizes the results of our baseline simulation, which focuses on the income tax, social insurance contributions (or payroll taxes) paid by employees and benefits. Consider first the income shock. Approximately $38 \%$ of such a shock would be absorbed by automatic stabilizers in the EU (and Euroland). For the US, we find a slightly lower value of $32 \%$. This difference of just six percentage points is surprising in so far as automatic stabilizers in Europe are usually considered to be drastically higher than in the US. ${ }^{15}$ Our results qualify this view to a certain degree, at least as far as proportional income shocks are concerned. Figure 1 shows that taxes and social insurance contributions are the dominating factors which drive $\tau$ in case of a uniform income shock. Benefits are of minor importance in this scenario.

In the case of the unemployment shock, the difference between the EU and the US is larger. EU automatic stabilizers now absorb $48 \%$ of the shock (in the Euro zone, we are close to 50\%) whereas the stabilization effect in the US is only $34 \%$. This difference can be explained with the importance of unemployment benefits which account for a large part of stabilization in Europe in this scenario. Table 7 in the Appendix shows that benefits alone absorb 19\% of the shock in Europe compared to just $7 \%$ in the US.

How does this cushioning of shocks translates into demand stabilization? The results for stabilization of aggregate demand are shown in Figure 2. The demand stabilization coefficients are lower than the income stabilization coefficients since demand stabilization can only be achieved for liquidity constrained households.

selecting the individuals with the highest probabilities when controlling for the same characteristics in the reweighting estimation (see Herault (2009)). The reweighting procedure is to some extent sensitive to changes in control variables. However, this mainly affects the distribution of the shock (which we do not analyze) and not the overall or mean effects which are important for the analysis in this paper.

${ }^{15}$ Note that for the US the value of the stabilization coefficient for the federal income tax only is below 25\% which is in line with the results of Auerbach and Feenberg (2000). 
Figure 1: Decomposition of stabilization coefficient for both scenarios

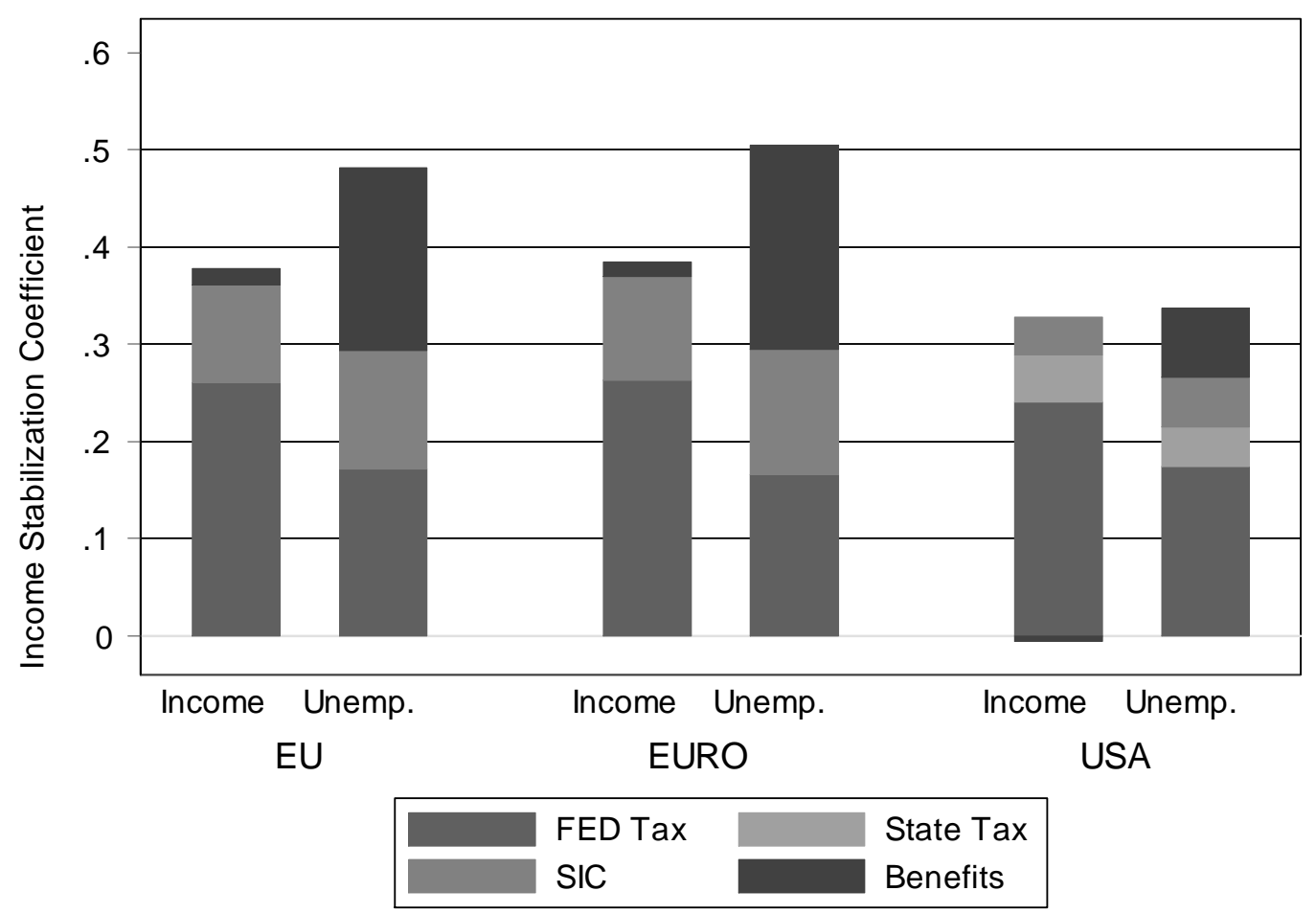

Source: Own calculations based on EUROMOD and TAXSIM

Therefore, the picture changes significantly. For the EU, the cushioning effect of automatic stabilizers is now equal to $26 \%$. For the US, we find a value of $19 \%, 7$ percentage points less than for the EU. For the Euro area, where fewer households are identified to be credit constrained, the demand stabilization coefficient (24\%) is lower than for the EU-group. For the unemployment shock, the picture again changes completely. In the EU, the stabilization effect is equal to $35 \%$, the Euro area is slightly lower (34\%), whereas the value for the US (19\%) is close to the value for the income shock. These results suggest that the transfers to the unemployed, in particular the rather generous systems of unemployment insurance in Europe, play a key role for demand stabilization and drive the difference in automatic stabilizers between Europe and the US. 
Figure 2: Stabilization coefficient with and without liquidity constraints

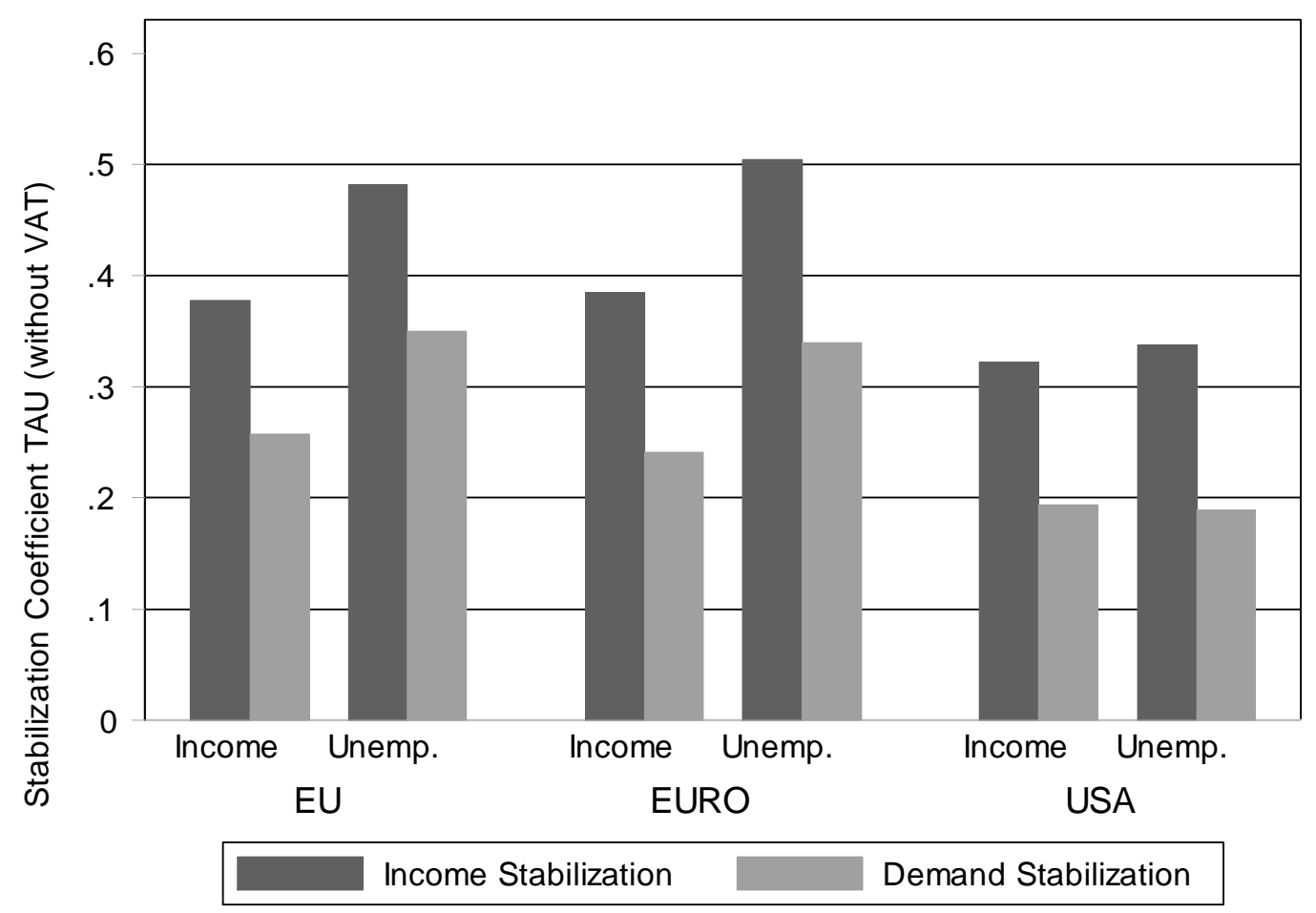

Source: Own calculations based on EUROMOD and TAXSIM

\subsection{Country decomposition}

The results for the stabilization coefficient vary considerably across countries, as can be seen from Figure 3 (and Tables 6 and 7 in the Appendix). In the case of the income shock, we find the highest stabilization coefficient for Denmark, where automatic stabilizers cushion $56 \%$ of the shock. Belgium (53\%), Germany (48\%) and, surprisingly, Hungary (48\%) also have strong automatic stabilizers. The lowest values are found for Estonia (25\%), Spain (28\%) and Greece (29\%). With the exception of France, taxes seem to have a stronger stabilizing role than social security contributions.

In case of the unemployment shock, the stabilization coefficients are getting larger in the majority of countries. Again, the highest value emerges for Denmark (71\%), followed by Sweden (69\%), Austria (67\%) Belgium (66\%) and Germany (65\%). The relatively low value of stabilization from (unemployment) benefits in Finland 
compared to its neighboring Nordic countries might be surprising at a first glance but can be explained with the fact that Finland has the least generous unemployment benefits of the Nordic countries (see Aaberge et al. (2000)). Hungary (46\%) is now below the EU average (48\%) due to the very low level of unemployment benefits. At the other end of the spectrum, there are some countries with values far below the US level of 34\%. These include Estonia (17\%), Spain (28\%), Poland (30\%) and, to a lesser extent, Italy (36\%). The negative stabilization coefficient for benefits in Estonia and Poland can be explained with the fact that the majority of benefits is conditional on working.

Figure 3: Decomposition of income stabilization coefficient in both scenarios for different countries

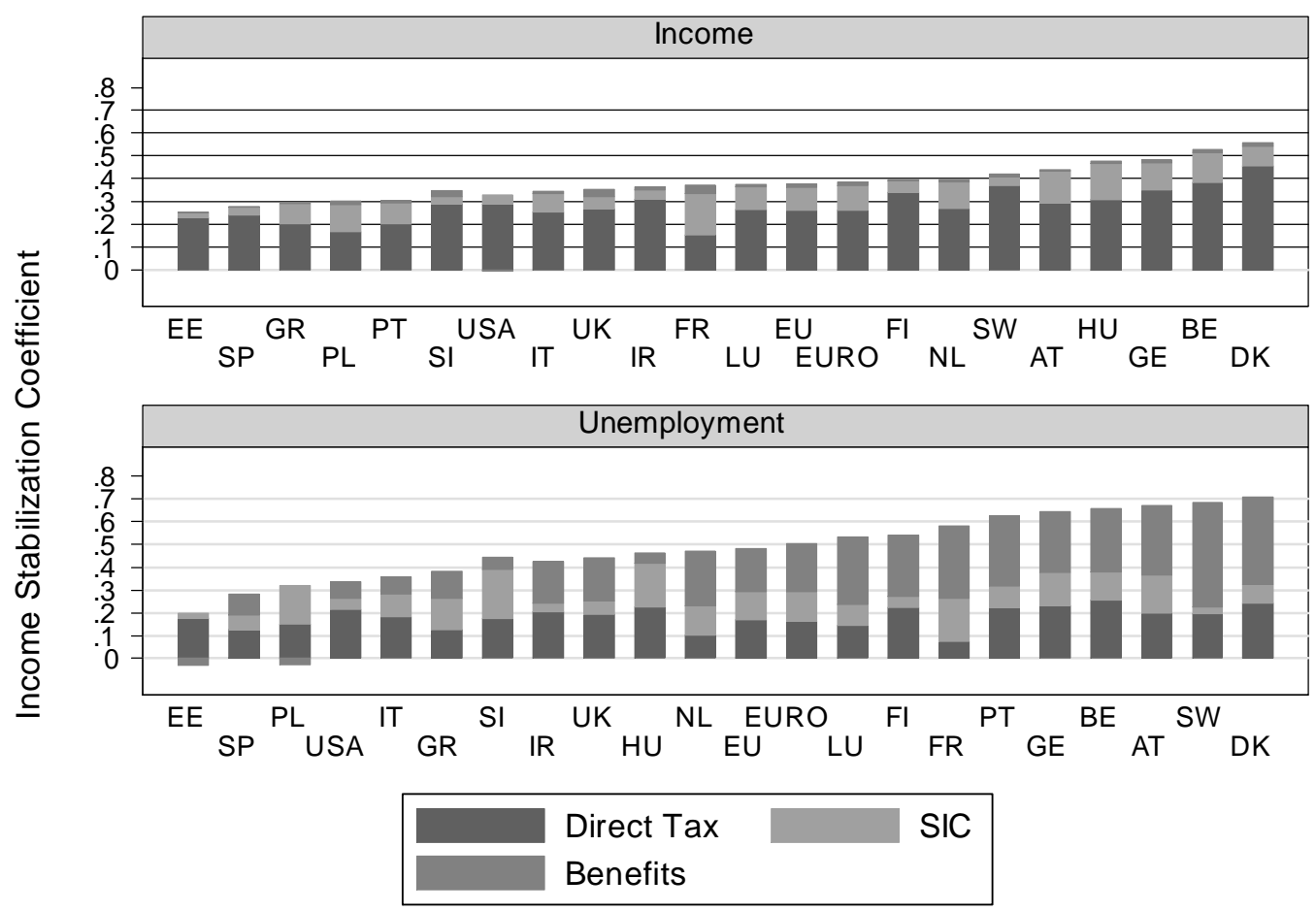

Source: Own calculations based on EUROMOD and TAXSIM

When looking only at the personal income tax, it is surprising that the values for the US (federal and state level tax) are higher than the EU average. This qualifies to some extent the view that tax progressivity is higher in Europe (e.g., Alesina and Glaeser (2004) or Piketty and Saez (2007)). Of course, this can be 
partly explained with the large heterogeneity within Europe. But still, only a few countries like Belgium, Germany and the Nordic countries have higher contributions of stabilization coming from the personal income tax.

How does this stabilization of disposable incomes affect household demand? In most Eastern European countries, households are more likely to be credit constrained than in Western Europe because financial wealth is typically lower. Our estimates confirm this as can be seen from the first column of Table $1 .{ }^{16}$ For this reason automatic stabilizers will be more important for demand stabilization in these countries. This explains why we find the highest modified demand stabilization coefficient for Hungary (46\%) and why we find a stabilization effect which is above or near to the EU average even for Poland (30\%) and Estonia (25\%), although disposable income stabilization is below the EU average in these countries. Relatively low values for automatic stabilization effects of the tax and transfer systems on demand are now found in countries where households are relatively wealthy, so that credit constraints are less important. These include Sweden, with a stabilization coefficient of $26 \%$, Germany (25\%) and in particular France (16\%). Our results, including those for other individual EU countries, are summarized in Table $1 .^{17}$

\subsection{Extension: Employer contributions and consumption taxes}

One objection to our results could be that we neglect some taxes which are potentially relevant as automatic stabilizers. These include consumption taxes like the value added tax or sales taxes, as well as social insurance contributions or payroll taxes paid by employers, corporate income taxes and other taxes like e.g. property taxes. The stabilization of cash flows of corporations has implications for aggregate demand which differ substantially from the implications of stabilizing household disposable income and analyzing these implications would be beyond the scope of this paper. ${ }^{18}$ In this section we present results for the income stabilization coefficient including employer and employee social insurance contributions and consumption

\footnotetext{
${ }^{16}$ As liquidity-constrained households are those households with low wealth and thus typically low income, one can expect that their share of income is lower than their share in the total population. In our data, this is true for all countries (see column 2 of Table 1 ).

${ }^{17}$ The results are robust to other definitions of liquidity constraints - at least with respect to cross-country rankings (see also Appendix Table 8). Of course, the higher the share of liquidity constrained households the higher $\tau^{C}$.

${ }^{18}$ This issue is discussed in Devereux and Fuest (forthcoming) and Buettner and Fuest (2009).
} 
Table 1: Stabilization of aggregate demand

\begin{tabular}{|c|c|c|c|c|c|c|}
\hline & \multicolumn{2}{|c|}{ Share liquidity constrained } & \multicolumn{2}{|c|}{ Income shock } & \multicolumn{2}{|c|}{ Unemployment shock } \\
\hline & Population & Income & $\tau$ Income & $\tau^{C}$ Demand & $\tau$ Income & $\tau^{C}$ Demand \\
\hline $\mathrm{AT}$ & 0.891 & 0.883 & 0.439 & 0.388 & 0.670 & 0.606 \\
\hline $\mathrm{BE}$ & 0.706 & 0.639 & 0.527 & 0.348 & 0.657 & 0.466 \\
\hline DK & 0.619 & 0.576 & 0.558 & 0.320 & 0.707 & 0.470 \\
\hline $\mathrm{EE}$ & 0.984 & 0.969 & 0.253 & 0.246 & 0.168 & 0.162 \\
\hline FI & 0.741 & 0.629 & 0.396 & 0.266 & 0.541 & 0.385 \\
\hline FR & 0.479 & 0.420 & 0.370 & 0.161 & 0.582 & 0.341 \\
\hline GE & 0.511 & 0.503 & 0.481 & 0.248 & 0.645 & 0.376 \\
\hline GR & 0.854 & 0.822 & 0.291 & 0.234 & 0.383 & 0.310 \\
\hline $\mathrm{HU}$ & 0.976 & 0.961 & 0.476 & 0.457 & 0.464 & 0.452 \\
\hline IR & 0.736 & 0.646 & 0.363 & 0.228 & 0.425 & 0.315 \\
\hline IT & 0.762 & 0.733 & 0.346 & 0.283 & 0.359 & 0.268 \\
\hline $\mathrm{LU}$ & 0.773 & 0.768 & 0.374 & 0.284 & 0.533 & 0.419 \\
\hline NL & 0.706 & 0.657 & 0.397 & 0.264 & 0.472 & 0.348 \\
\hline PL & 0.985 & 0.982 & 0.301 & 0.296 & 0.295 & 0.288 \\
\hline PT & 0.899 & 0.886 & 0.303 & 0.273 & 0.625 & 0.589 \\
\hline SI & 0.743 & 0.632 & 0.317 & 0.112 & 0.425 & 0.245 \\
\hline SP & 0.837 & 0.824 & 0.277 & 0.225 & 0.283 & 0.230 \\
\hline SW & 0.630 & 0.599 & 0.420 & 0.257 & 0.685 & 0.501 \\
\hline UK & 0.824 & 0.775 & 0.352 & 0.277 & 0.441 & 0.397 \\
\hline $\mathrm{EU}$ & 0.717 & 0.686 & 0.378 & 0.258 & 0.482 & 0.350 \\
\hline EURO & 0.657 & 0.626 & 0.385 & 0.242 & 0.504 & 0.339 \\
\hline USA & 0.777 & 0.536 & 0.322 & 0.194 & 0.337 & 0.189 \\
\hline
\end{tabular}

Source: Own calculations based on EUROMOD and TAXSIM.

Note: A household is defined as liquidity constrained if its capitalized wealth is less than the disposable income of at least two months (cf. Zeldes (1989)).

taxes.

Comparing Table 2 with Table 6 and Table 3 with Table 7 , respectively, several interesting results become apparent. Clearly, stabilization through the consumption taxes strongly depends on their level. Thus, it is not surprising that high values for the stabilization coefficient of consumption taxes can be found for countries such as Denmark, Estonia, Finland, Ireland, the Netherlands or Slovenia which all belong to the group of countries with high levels of indirect taxation. In contrast, the respective coefficient for the US is at the lower end.

With regard to the new values of stabilization throug employer SIC, it becomes evident that the gap between the EU and the US widens substantially. Comparing 
results with and without employer social insurance contributions, we find for stabilization through SIC that the EU-US gap has increased by roughly 10 percentage points in both scenarios. As a consequence, overall stabilization, shown in the last column of Tables 2 and 3 (and Tables 6 and 7 in the Appendix), is now significantly higher in Europe compared with the US not only in the unemployment, but also in the income shock scenario. Hence, expanding the set of taxes by employer social insurance contributions and consumption taxes, we find an increasing gap in automatic stabilization between the EU and the US for both shock scenarios.

Table 2: Decomposition income scenario with employer and employee SIC and CT

\begin{tabular}{llllllll}
\hline \hline & FEDTax & StateTax & SIC & BEN & TaxSicBen & CT & TSBCT \\
\hline AT & 0.253 & 0.000 & 0.258 & 0.006 & 0.517 & 0.107 & 0.624 \\
BE & 0.317 & 0.000 & 0.278 & 0.012 & 0.607 & 0.084 & 0.691 \\
DK & 0.447 & 0.000 & 0.101 & 0.017 & 0.566 & 0.145 & 0.711 \\
EE & 0.174 & 0.000 & 0.257 & 0.003 & 0.433 & 0.126 & 0.559 \\
FI & 0.281 & 0.000 & 0.215 & 0.005 & 0.501 & 0.140 & 0.641 \\
FR & 0.092 & 0.000 & 0.508 & 0.022 & 0.622 & 0.077 & 0.699 \\
GE & 0.314 & 0.000 & 0.211 & 0.010 & 0.535 & 0.086 & 0.622 \\
GR & 0.187 & 0.000 & 0.157 & 0.000 & 0.345 & 0.101 & 0.447 \\
HU & 0.243 & 0.000 & 0.335 & 0.007 & 0.585 & 0.110 & 0.695 \\
IR & 0.295 & 0.000 & 0.087 & 0.013 & 0.395 & 0.145 & 0.540 \\
IT & 0.210 & 0.000 & 0.238 & 0.011 & 0.458 & 0.094 & 0.552 \\
LU & 0.243 & 0.000 & 0.173 & 0.011 & 0.427 & 0.137 & 0.564 \\
NL & 0.267 & 0.000 & 0.124 & 0.011 & 0.402 & 0.145 & 0.547 \\
PL & 0.148 & 0.000 & 0.223 & 0.013 & 0.384 & 0.120 & 0.504 \\
PT & 0.170 & 0.000 & 0.239 & 0.009 & 0.417 & 0.115 & 0.533 \\
SI & 0.287 & 0.000 & 0.038 & 0.028 & 0.321 & 0.160 & 0.481 \\
SP & 0.205 & 0.000 & 0.175 & 0.001 & 0.382 & 0.098 & 0.479 \\
SW & 0.286 & 0.000 & 0.254 & 0.010 & 0.549 & 0.120 & 0.669 \\
UK & 0.246 & 0.000 & 0.128 & 0.029 & 0.403 & 0.115 & 0.518 \\
\hline EU & 0.223 & 0.000 & 0.241 & 0.014 & 0.478 & 0.101 & 0.579 \\
EURO & 0.222 & 0.000 & 0.265 & 0.011 & 0.497 & 0.095 & 0.592 \\
USA & 0.240 & 0.049 & 0.077 & -0.006 & 0.360 & 0.031 & 0.392 \\
\hline \hline
\end{tabular}

\section{Discussion of the results}

In this section, we discuss a number of possible objections to and questions raised by our analysis. These include the relation of our results to widely used macro 
Table 3: Decomposition unemployment scenario with employer and employee SIC and $\mathrm{CT}$

\begin{tabular}{llllllll}
\hline & FEDTax & StateTax & SIC & BEN & TaxSicBen & CT & TSBCT \\
\hline AT & 0.169 & 0.000 & 0.297 & 0.256 & 0.721 & 0.062 & 0.783 \\
BE & 0.217 & 0.000 & 0.262 & 0.232 & 0.711 & 0.062 & 0.772 \\
DK & 0.239 & 0.000 & 0.095 & 0.377 & 0.711 & 0.097 & 0.808 \\
EE & 0.133 & 0.000 & 0.270 & -0.024 & 0.379 & 0.138 & 0.517 \\
FI & 0.183 & 0.000 & 0.223 & 0.218 & 0.625 & 0.106 & 0.730 \\
FR & 0.047 & 0.000 & 0.501 & 0.195 & 0.743 & 0.052 & 0.795 \\
GE & 0.202 & 0.000 & 0.253 & 0.234 & 0.690 & 0.058 & 0.747 \\
GR & 0.118 & 0.000 & 0.195 & 0.111 & 0.424 & 0.089 & 0.514 \\
HU & 0.179 & 0.000 & 0.361 & 0.037 & 0.577 & 0.112 & 0.689 \\
IR & 0.198 & 0.000 & 0.077 & 0.174 & 0.449 & 0.132 & 0.581 \\
IT & 0.150 & 0.000 & 0.262 & 0.062 & 0.475 & 0.091 & 0.565 \\
LU & 0.137 & 0.000 & 0.157 & 0.274 & 0.567 & 0.103 & 0.671 \\
NL & 0.093 & 0.000 & 0.215 & 0.216 & 0.523 & 0.115 & 0.639 \\
PL & 0.130 & 0.000 & 0.285 & -0.023 & 0.392 & 0.118 & 0.511 \\
PT & 0.193 & 0.000 & 0.221 & 0.263 & 0.677 & 0.064 & 0.741 \\
SI & 0.154 & 0.000 & 0.311 & 0.048 & 0.495 & 0.119 & 0.614 \\
SP & 0.103 & 0.000 & 0.245 & 0.074 & 0.422 & 0.091 & 0.513 \\
SW & 0.151 & 0.000 & 0.257 & 0.350 & 0.759 & 0.064 & 0.823 \\
UK & 0.181 & 0.000 & 0.123 & 0.174 & 0.477 & 0.100 & 0.578 \\
\hline EU & 0.146 & 0.000 & 0.269 & 0.153 & 0.568 & 0.083 & 0.651 \\
EURO & 0.138 & 0.000 & 0.296 & 0.166 & 0.600 & 0.074 & 0.674 \\
USA & 0.174 & 0.041 & 0.102 & 0.071 & 0.388 & 0.030 & 0.418 \\
\hline \hline
\end{tabular}

indicators of automatic stabilizers, the role of other taxes, the correlation between automatic stabilizers and other macro variables like e.g. openness and, finally, the correlations between discretionary fiscal stimulus programs and automatic stabilizers as well as openness.

\subsection{Stabilization coefficients and simple macro indicators}

One could argue that aggregate measures like e.g. the tax revenue to GDP ratio reveal sufficient information on the magnitude of automatic stabilizers in the different countries. For instance, the IMF (2009) has recently used aggregate tax to GDP ratios as proxies for the size of automatic stabilizers in G-20 countries. The upper panel of Figure 4 depicts the relation between the ratio of average revenue 2006-2010 
to GDP and the income stabilization coefficient for the proportional income shock. ${ }^{19}$ With a correlation of 0.58 , one can conclude that government size is indeed a good predictor for the amount of automatic stabilization. The picture changes, however, if stabilization of aggregate household demand is considered, i.e. if we account for liquidity constraints. As shown in Figure 4 (lower panel), with a coefficient of 0.33 government size and stabilization of aggregate household demand are only weakly correlated. $^{20}$

Figure 4: Government size and income and demand stabilization coefficients
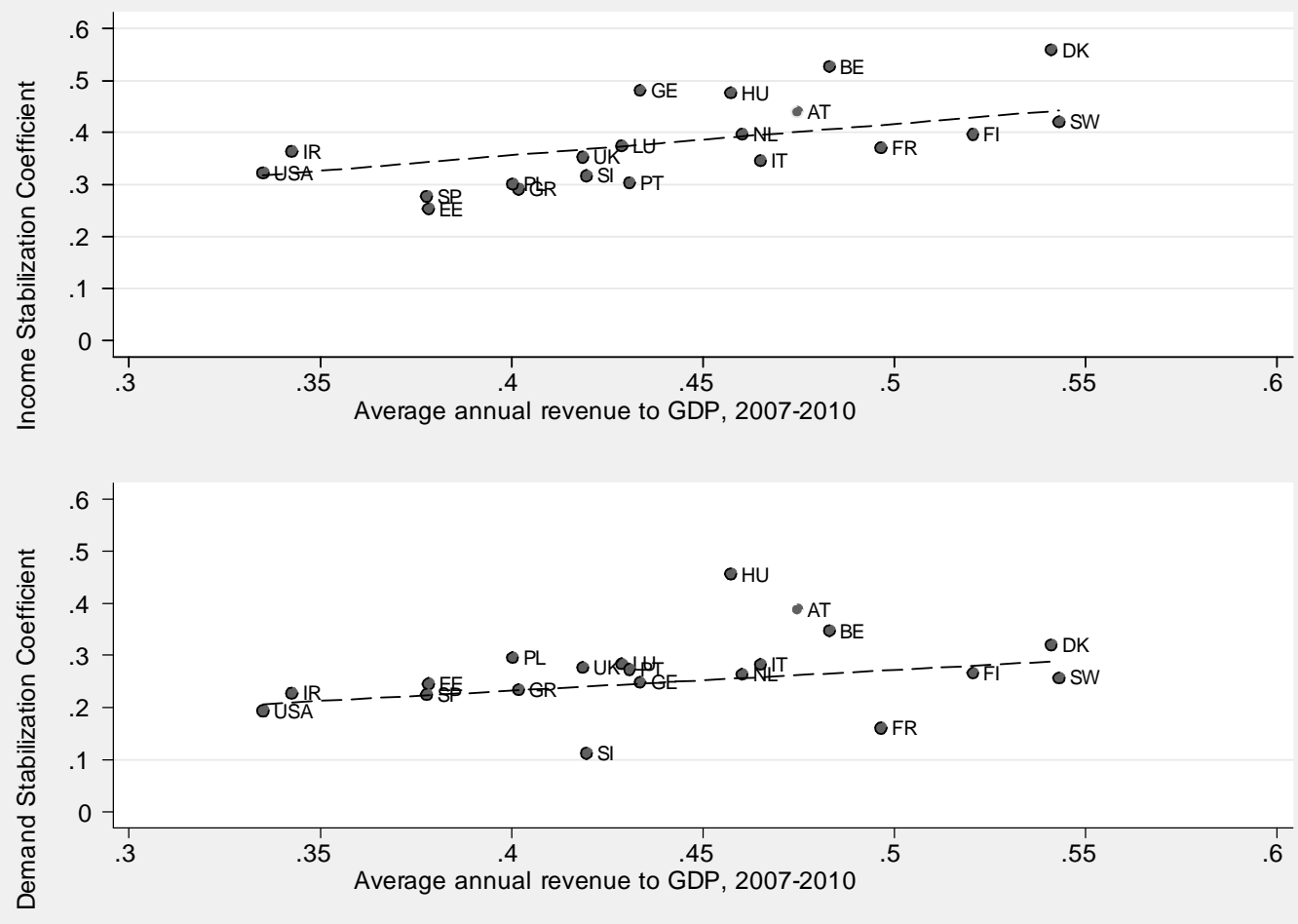

Source: Own calculations based on EUROMOD and TAXSIM, European Commission (2009a).

These simple correlations suggest that macro indicators like tax revenue to GDP ratios are meaningful indicators for the stabilization effect of the tax and transfer

\footnotetext{
${ }^{19}$ All figures and correlations in this section are population-weighted in order to control for different country sizes. However, results are similar to those without population-weighting. We also obtained similar results when using the government spending to GDP ratio instead of revenue as a measure of the size of the government.

${ }^{20}$ The respective correlations for the unemployment shock are 0.72 and 0.52 .
} 
system on disposable income but can be misleading as indicators of the stabilization effect on household demand. The reason is that the latter depends on the presence of liquidity constraints. The income share of liquidity constrained households, however, is negatively correlated with the size of government. In our analysis, we find a correlation of -0.30 (see also Figure 7 in the Appendix).

Another interesting point arises from Figure 4 when making vertical comparisons between similar countries. For instance, Denmark and Sweden, and - to some extent - Belgium and France have similar levels of revenue to GDP ratios. However, the stabilization is higher in Denmark and Belgium. In both countries, the importance of the (progressive) income tax is higher, whereas Sweden and France rely more on proportional social insurance contributions. Therefore, not only the size but also the structure of the tax benefit system are important for its possibilities of automatic stabilization.

\subsection{Automatic stabilizers and openness}

It is a striking feature of our results that automatic stabilizers differ significantly within Europe. In particular, automatic stabilizers in Eastern and Southern European countries are much weaker than in the rest of Europe. One factor contributing to this is that government size is often positively correlated with per capita incomes, at least in Europe. The stabilization of disposable incomes will therefore be higher in high income countries, just as a side effect of a larger public sector.

But differences in automatic stabilizers across countries may also have other reasons. In particular, the effectiveness of demand stabilization as a way of stabilizing domestic output is smaller, the more open the economy. In very open economies, domestic output will depend heavily on export demand and higher demand by domestic households will partly lead to higher imports. Clearly, openness of the economy has a number of other implications for the tax and transfer system, including the view that more open economies need more insurance against shocks as argued, e.g., by Rodrik (1998). Figure 5 depicts the relationship between income stabilization coefficients and openness as measured by the ratio of exports plus imports over GDP. As graph 5 shows, it is not the case that more open economies have weaker automatic stabilizers, the correlation is even positive (0.57). Our results thus support the hypothesis of Rodrik (1998) that income stabilization is higher in more open economies. For the demand stabilization coefficient, we find a similar correlation. 
Figure 5: Income stabilization coefficient and openness of the economy

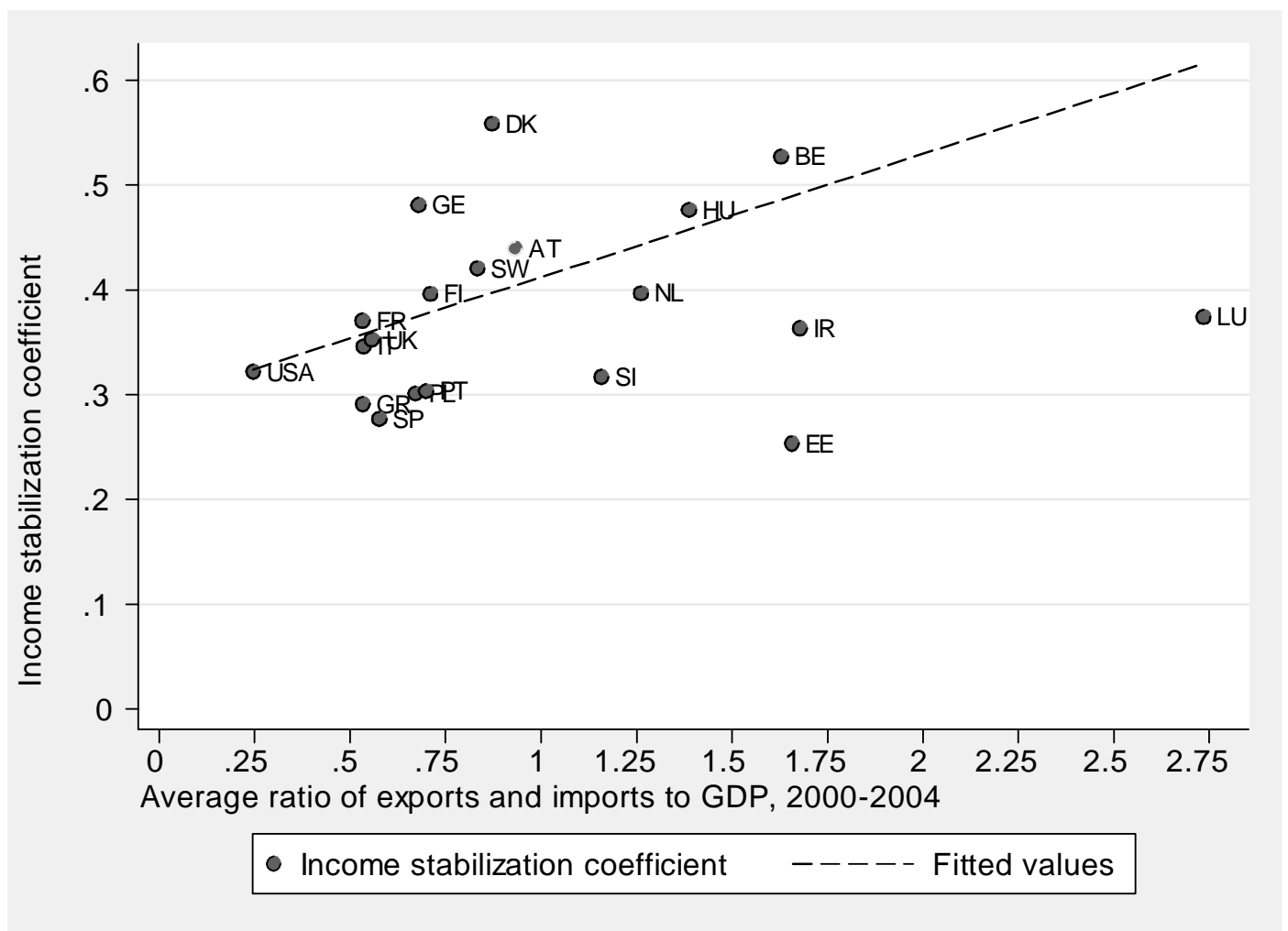

Source: Own calculations based on EUROMOD and TAXSIM, Heston et al. (2006).

\subsection{Automatic stabilizers and discretionary fiscal policy}

In the debate on fiscal policy responses to the crisis, some countries have been criticized for being reluctant to enact fiscal stimulus programs in order to stabilize demand, in particular Germany. One reaction to this criticism was to point to the fact that automatic stabilizers in Germany are more important than in other countries, so that less discretionary action is required. This raises the general question of whether countries with weaker automatic stabilizers have taken more discretionary fiscal policy action. To shed some light on this issue, we relate the size of fiscal stimulus programs to stabilization coefficients.

Graph 6 shows that income stabilization coefficients are largely uncorrelated to the size of fiscal stimulus programs (-0.10). A larger negative correlation emerges when we consider demand stabilization coefficients (see Graph 8 in the Appendix). Our finding of a small correlation between automatic stabilizers and discretionary 
Figure 6: Discretionary measures and income stabilization coefficient

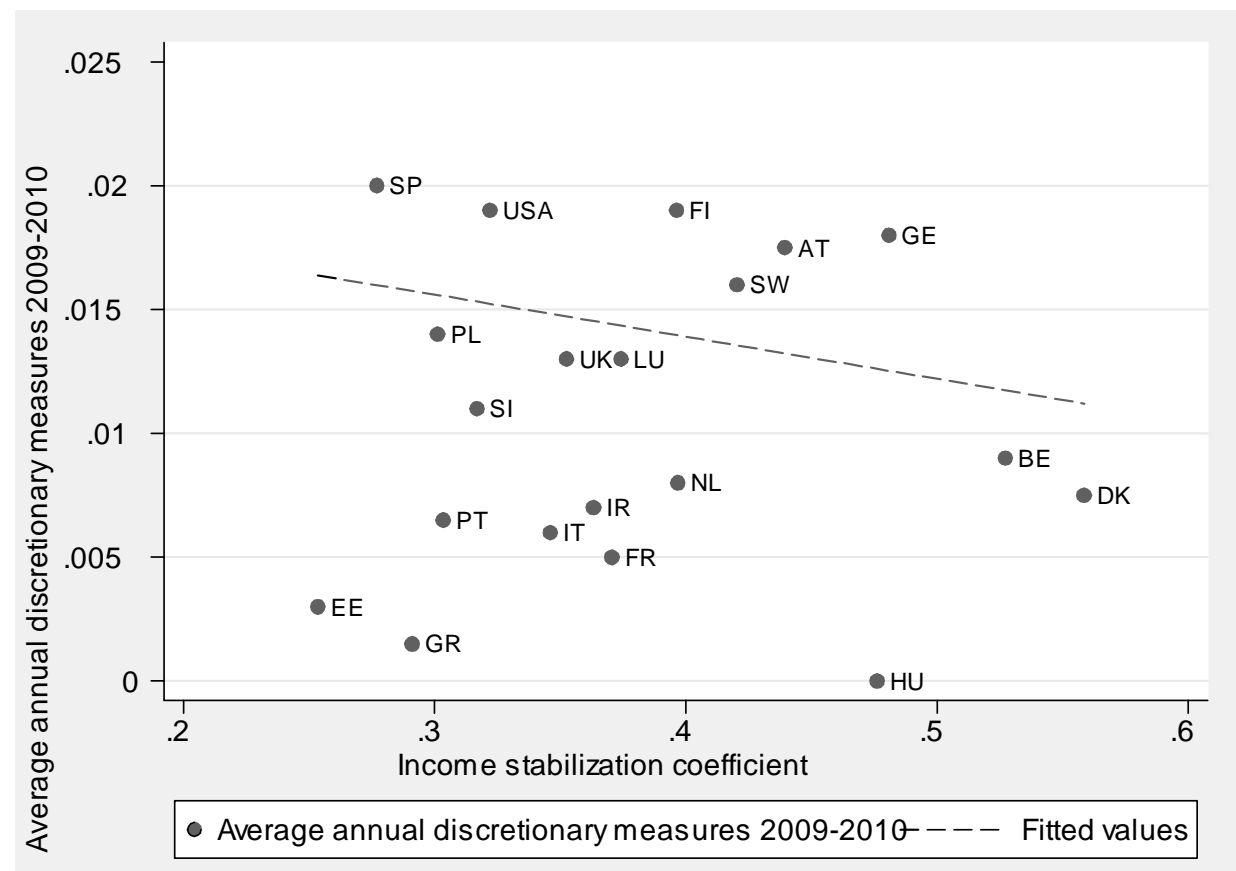

Source: Own calculations based on EUROMOD and TAXSIM, European Commission (2009c), IMF (2009) and International Labour Office and International Institute for Labour Studies (2009).

measures qualifies the view that countries with lower automatic stabilizers have engaged in more discretionary fiscal policy action (e.g., IMF (2009), p. 27).

A further concern in the policy debate put forward by supporters of large and coordinated discretionary measures is that countries could limit the size of their programs at the expense of countries with more generous fiscal policy responses. The idea behind this argument is that some countries might show a free-rider behavior and profit from spill-over effects of discretionary measures. ${ }^{21}$ Therefore, we investigate the hypothesis if more open countries which are supposed to benefit more from spill-over effects indeed passed smaller stimulus programs. We find a negative correlation of -0.40 between the average annual discretionary measures in 2009 and 2010 and the coefficient for openness which supports the hypothesis. ${ }^{22}$

\footnotetext{
${ }^{21}$ In that sense, a fiscal stimulus program can be seen as a positive externality since potential positive effects are not limited to the country of origin.

${ }^{22} \mathrm{Cf}$. Graph 9 in the Appendix. A multivariate regression of discretionary measures on the income stabilization coefficients, a measure of openness of the respective economies and their
} 


\section{Effects on income distribution (preliminary)}

After having analyzed the shock absorption capacities of the tax and transfer systems in Europe and the US, the logical next step is to consider the distributional consequences of the shock scenarios. A precise analysis on distributional effects of the economic crisis of 2008-2009 has to wait until more recent data are available. Nevertheless, it is interesting to note that the shock scenarios analyzed in this paper lead to somewhat different implications for the income distribution as is shown in Tables 4 and 5. Both tables report percentage changes in inequality measures (Gini and the Generalized Entropy Measures 0-2) and in headcount measures for being poor or rich. ${ }^{23}$ While the proportional income shock leads to reductions in all inequality measures, the overall picture for the asymmetric unemployment shock is not that clear. In some countries, this shock scenario leads to an increase in inequality indicating that distributional implications crucially depend on which income groups are hardest hit by unemployment and income losses. If low income groups are the first who loose their jobs during a recession, one can expect an increase in inequality. However, if also middle or upper income groups are affected which seems to be relevant especially in long-lasting recessions such as the current one, distributional implications become more ambiguous. Therefore, future research will need to show which distributional implications can be drawn from the current economic crisis.

governments' budget balance in 2007 leads to significant coefficients of openness and the budget balance; whereas the relationship between discretionary fiscal policy and the amount of automatic stabilization remains insignificant. This result indicates that in addition to the argument above about openness, some governments have been constrained by weak budget positions in their decision making about discretionary fiscal policy. However, due to the very small sample size, this inference should be interpreted with caution.

${ }^{23}$ Note that a family is counted as poor if its equivalised disposable income is lower than $60 \%$ of the mean equivalised disposable income and as rich if its income exceeds twice the mean. 
Table 4: Effect of proportional income shock on income distribution

\begin{tabular}{lllllll}
\hline \hline & Gini & GE0 & GE1 & GE2 & Poor & Rich \\
\hline at & -1.297 & -2.633 & -2.352 & -2.167 & 4.760 & -12.088 \\
be & -2.270 & -4.023 & -4.129 & -4.603 & 2.673 & -16.241 \\
dk & -2.064 & -3.063 & -3.459 & -3.851 & 3.838 & -18.903 \\
ee & -1.622 & -3.734 & -3.062 & -3.184 & 4.529 & -11.508 \\
fi & -1.806 & -3.324 & -3.066 & -3.926 & 5.622 & -13.981 \\
fr & -1.422 & -2.811 & -2.492 & -2.462 & 7.458 & -9.947 \\
ge & -1.489 & -3.102 & -2.821 & -2.838 & 4.141 & -12.982 \\
gr & -0.338 & -0.683 & -0.819 & -1.181 & 7.288 & -11.355 \\
hu & -0.604 & -1.097 & -1.675 & -2.768 & 5.701 & -9.241 \\
ir & -1.335 & -3.017 & -2.639 & -2.989 & 3.701 & -12.591 \\
it & -0.735 & -1.076 & -1.478 & -1.840 & 4.910 & -5.857 \\
lu & -1.233 & -2.590 & -2.684 & -3.112 & 9.994 & -14.276 \\
nl & -1.232 & -2.507 & -2.233 & -2.084 & 10.629 & -16.256 \\
pl & -0.923 & -1.917 & -2.115 & -2.671 & 6.749 & -9.692 \\
pt & -0.611 & -1.578 & -1.093 & -1.013 & 4.693 & -6.055 \\
si & -0.318 & -0.650 & -0.892 & -1.395 & 0.273 & -1.290 \\
sp & -0.693 & -1.091 & -1.261 & -1.390 & 6.343 & -13.806 \\
sw & -2.050 & -3.585 & -3.305 & -3.025 & 4.215 & -15.446 \\
uk & -2.219 & -4.439 & -3.912 & -3.756 & 3.753 & -13.001 \\
\hline \hline
\end{tabular}

Source: Own calculations based on EUROMOD and TAXSIM 
Table 5: Effect of unemployment shock on income distribution

\begin{tabular}{cllllll}
\hline \hline & Gini & GE0 & GE1 & GE2 & Poor & Rich \\
\hline at & 0.304 & 0.964 & 0.713 & 0.688 & 4.421 & -3.619 \\
be & 0.126 & -0.258 & -0.250 & -0.230 & 3.869 & -4.322 \\
dk & -0.218 & -0.505 & 1.515 & 6.731 & 1.176 & -5.054 \\
ee & 0.914 & 1.971 & 1.808 & 1.976 & 6.542 & -2.989 \\
fi & 0.347 & 0.340 & -0.355 & -1.537 & 7.104 & -3.428 \\
fr & 0.210 & 0.371 & 0.428 & 0.479 & 4.083 & -2.409 \\
ge & 0.445 & 0.675 & 0.846 & 1.006 & 6.245 & -3.469 \\
gr & 0.166 & 0.168 & 0.352 & 0.519 & 2.509 & -2.820 \\
hu & 0.518 & 1.077 & 0.988 & 1.304 & 5.612 & -3.861 \\
ir & 1.154 & 1.566 & 0.995 & -1.235 & 10.295 & -7.285 \\
it & 0.507 & 1.463 & 0.969 & 1.185 & 3.567 & -2.234 \\
lu & -0.225 & -0.447 & -0.152 & 0.186 & 1.335 & -3.843 \\
nl & 0.652 & 2.095 & 1.327 & 1.115 & 7.892 & -3.985 \\
pl & 0.281 & 0.690 & 0.290 & 0.010 & 3.757 & -2.639 \\
pt & -0.709 & -1.435 & -1.556 & -1.912 & 1.528 & -2.667 \\
si & 0.327 & 0.583 & 0.503 & 0.429 & 4.354 & -2.931 \\
sp & 0.590 & 1.455 & 1.173 & 1.327 & 3.545 & -3.003 \\
sw & -0.037 & -0.329 & -0.213 & -0.523 & 3.406 & -3.177 \\
uk & 1.074 & 2.053 & 2.119 & 2.386 & 7.895 & -2.873 \\
\hline \hline Surce: & Own calculations based on EUROMOD and TAXSIM
\end{tabular}




\section{Conclusions}

In this paper we have used the microsimulation models for the tax and transfer systems of 19 European countries (EUROMOD) and the US (TAXSIM) to investigate the extent to which automatic stabilizers cushion household disposable income and household demand in the event of macroeconomic shocks. Our analysis has first focused on the personal income tax, employee social insurance contributions and benefits, then an extended analysis including employer social insurance contributions and consumption taxes has been presented. One of the key findings of our analysis is that the amount of automatic stabilization depends strongly on the type of income shock. In the case of a proportional income shock, approximately $38 \%$ of the shock would be absorbed by automatic stabilizers in the EU. For the US, we find a value of $32 \%$. Within the EU, there is considerable heterogeneity, and results range from a value of $25 \%$ for Estonia to $56 \%$ for Denmark. In general automatic stabilizers in Eastern and Southern European countries are considerably lower than in Continental and Northern European countries.

In the case of an unemployment shock, which affects households asymmetrically, the difference between the EU and the US is larger. EU automatic stabilizers absorb $48 \%$ of the shock whereas the stabilization effect in the US is only $34 \%$. Again, there is considerable heterogeneity within the EU.

These results suggest that social transfers, in particular the rather generous systems of unemployment insurance in Europe, play a key role for the stabilization of disposable incomes and household demand and explain a large part of the difference in automatic stabilizers between Europe and the US. This is confirmed by the decomposition of stabilization effects in our analysis. In the case of the unemployment shocks, benefits alone absorb $19 \%$ of the shock in Europe compared to just $7 \%$ in the US, whereas the stabilizing effect of income taxes (taking into account State taxes in the US as well) is similar. This qualifies to some extent the view that the tax wedge is larger in Europe than in the US. This is only true when looking at the high tax countries like Belgium, Denmark, Finland, Germany or Sweden.

How does this cushioning of shocks translate into demand stabilization? Since demand stabilization can only be achieved for liquidity constrained households, the picture changes significantly. For the income shock, the cushioning effect of automatic stabilizers is now equal to $26 \%$ in the EU. For the US, we find a value of $19 \%$, which is again rather similar. The value for the Euro area $(24 \%)$ is close to the value 
for the EU. For the unemployment shock, however, we find a large difference. In the EU, the stabilization effect is equal to $35 \%$ whereas the value for the US (19\%) is close to the value for the income shock.

Does this mean that the US economy is particularly vulnerable to the current economic crisis? To the extent that wages are more flexible than in Europe, one could hope that fewer jobs will be lost in the crisis, so that the proportional income scenario is more relevant. But US labor markets are also characterized by less employment protection, so that job losses occur more quickly. For instance, between April 2008 and April 2009, the US unemployment rate increased by 3.9 percentage points while the unemployment rate in the Euro area only increased by less than two percentage points. There is much less automatic stabilization of disposable incomes as well as household consumption demand than in Europe.

A second major result from our analysis is that demand stabilization differs considerably from disposable income stabilization. This has important policy implications, also for discretionary fiscal policy. As low income households are more likely to be liquidity constrained and have a higher propensity of spending an income increase, policies aimed at those households should lead to higher stabilizing effects. If liquidity constraints are low, reducing tax rates in order to tackle the crisis will not be successful in increasing aggregate demand (see also Shapiro and Slemrod (2009)). In this case, increasing government expenditure might be a more successful way of tackling the crisis.

A third important result of our analysis is that automatic stabilizers are very heterogenous within Europe. Interestingly, Eastern and Southern European countries are characterized by rather low automatic stabilizers. This is surprising, at least from an insurance point of view because lower average income (and wealth) implies that households are more vulnerable to income shocks. One explanation for this finding could be that countries with lower per capita incomes tend to have smaller public sectors. From this perspective, weaker automatic stabilizers in Eastern and Southern European countries are a potentially unintended side effect of the lower demand for government activity including redistribution. Another potential explanation, the idea that more open economies have weaker automatic stabilizers because domestic demand spills over to other countries, seems to be inconsistent with the data, at least as far as the simple correlation between stabilization coefficients and trade to GDP ratios is concerned.

Finally, we have discussed the claim that countries with smaller automatic sta- 
bilizers have engaged in more discretionary fiscal policy action. According to our results, there is no correlation between fiscal stimulus programs of individual countries and stabilization coefficients. However, we find that more open countries and countries with higher budget deficits have passed smaller stimulus programs. All in all, our results suggest that policymakers did not take into account the forces of automatic stabilizers when designing active fiscal policy measures to tackle the current economic crisis.

These results have to be interpreted in the light of various limitations of our analysis. Firstly, the role of tax and transfer systems for stabilizing household demand, not just disposable income, is based on strong assumptions on the link between disposable income and household expenditures. Although we have used what we believe to be the best available method for estimating liquidity constraints, considerable uncertainty remains as to whether this method leads to an appropriate description of household behavior. Secondly, our analysis abstracts from automatic stabilization through other taxes, in particular corporate income taxes. Thirdly, we have abstracted from the role of labor supply or other behavioral adjustments for the impact of automatic stabilizers. We intend to pursue these issues in future research.

\section{A Appendix:}

\section{A.1 Additional results}


Table 6: Decomposition income scenario

\begin{tabular}{llllll}
\hline \hline & FEDTax & StateTax & SIC & BEN & TaxSicBen \\
\hline AT & 0.294 & 0.000 & 0.139 & 0.006 & 0.439 \\
BE & 0.382 & 0.000 & 0.131 & 0.014 & 0.527 \\
DK & 0.455 & 0.000 & 0.086 & 0.018 & 0.558 \\
EE & 0.228 & 0.000 & 0.021 & 0.004 & 0.253 \\
FI & 0.340 & 0.000 & 0.050 & 0.006 & 0.396 \\
FR & 0.153 & 0.000 & 0.181 & 0.036 & 0.370 \\
GE & 0.351 & 0.000 & 0.118 & 0.012 & 0.481 \\
GR & 0.203 & 0.000 & 0.088 & 0.000 & 0.291 \\
HU & 0.307 & 0.000 & 0.160 & 0.009 & 0.476 \\
IR & 0.310 & 0.000 & 0.039 & 0.014 & 0.363 \\
IT & 0.254 & 0.000 & 0.079 & 0.013 & 0.346 \\
LU & 0.265 & 0.000 & 0.097 & 0.012 & 0.374 \\
NL & 0.270 & 0.000 & 0.116 & 0.011 & 0.397 \\
PL & 0.168 & 0.000 & 0.118 & 0.015 & 0.301 \\
PT & 0.203 & 0.000 & 0.090 & 0.010 & 0.303 \\
SI & 0.289 & 0.000 & 0.031 & 0.028 & 0.317 \\
SP & 0.240 & 0.000 & 0.035 & 0.001 & 0.277 \\
SW & 0.368 & 0.000 & 0.040 & 0.012 & 0.420 \\
UK & 0.267 & 0.000 & 0.054 & 0.031 & 0.352 \\
\hline EU & 0.260 & 0.000 & 0.100 & 0.017 & 0.378 \\
EURO & 0.263 & 0.000 & 0.108 & 0.015 & 0.385 \\
USA & 0.240 & 0.049 & 0.039 & -0.006 & 0.322 \\
\hline \hline Source: & Own calculations based $0 n$ EUROMOD and TAXSIM
\end{tabular}


Table 7: Decomposition unemployment scenario

\begin{tabular}{llllll}
\hline \hline & FEDTax & StateTax & SIC & BEN & TaxSicBen \\
\hline AT & 0.200 & 0.000 & 0.167 & 0.303 & 0.670 \\
BE & 0.257 & 0.000 & 0.124 & 0.276 & 0.657 \\
DK & 0.243 & 0.000 & 0.083 & 0.382 & 0.707 \\
EE & 0.178 & 0.000 & 0.022 & -0.032 & 0.168 \\
FI & 0.224 & 0.000 & 0.050 & 0.267 & 0.541 \\
FR & 0.076 & 0.000 & 0.190 & 0.317 & 0.582 \\
GE & 0.231 & 0.000 & 0.145 & 0.268 & 0.645 \\
GR & 0.126 & 0.000 & 0.137 & 0.119 & 0.383 \\
HU & 0.227 & 0.000 & 0.190 & 0.047 & 0.464 \\
IR & 0.207 & 0.000 & 0.036 & 0.182 & 0.425 \\
IT & 0.183 & 0.000 & 0.101 & 0.076 & 0.359 \\
LU & 0.147 & 0.000 & 0.090 & 0.296 & 0.533 \\
NL & 0.103 & 0.000 & 0.131 & 0.239 & 0.472 \\
PL & 0.151 & 0.000 & 0.170 & -0.027 & 0.295 \\
PT & 0.225 & 0.000 & 0.094 & 0.306 & 0.625 \\
SI & 0.175 & 0.000 & 0.216 & 0.054 & 0.425 \\
SP & 0.127 & 0.000 & 0.064 & 0.091 & 0.283 \\
SW & 0.197 & 0.000 & 0.029 & 0.458 & 0.685 \\
UK & 0.194 & 0.000 & 0.061 & 0.186 & 0.441 \\
\hline EU & 0.172 & 0.000 & 0.121 & 0.189 & 0.482 \\
EURO & 0.166 & 0.000 & 0.129 & 0.210 & 0.504 \\
USA & 0.174 & 0.041 & 0.051 & 0.071 & 0.337 \\
\hline \hline Source: & Own calculations based $0 n$ EUROMOD and TAXSIM
\end{tabular}


Table 8: Stabilization of aggregate demand

\begin{tabular}{|c|c|c|c|c|c|c|}
\hline & \multicolumn{2}{|c|}{ Share liquidity constrained } & \multicolumn{2}{|c|}{ Income shock } & \multicolumn{2}{|c|}{ Unemployment shock } \\
\hline & Population & Income & $\tau$ Demand & $\tau$ Income & $\tau$ Demand & $\tau$ Income \\
\hline $\mathrm{AT}$ & 0.750 & 0.408 & 0.172 & 0.439 & 0.396 & 0.670 \\
\hline $\mathrm{BE}$ & 0.750 & 0.352 & 0.190 & 0.527 & 0.368 & 0.657 \\
\hline DK & 0.750 & 0.387 & 0.205 & 0.558 & 0.392 & 0.707 \\
\hline $\mathrm{EE}$ & 0.750 & 0.350 & 0.087 & 0.253 & 0.073 & 0.168 \\
\hline FI & 0.750 & 0.364 & 0.136 & 0.396 & 0.314 & 0.541 \\
\hline FR & 0.750 & 0.379 & 0.143 & 0.370 & 0.383 & 0.582 \\
\hline GE & 0.750 & 0.374 & 0.172 & 0.481 & 0.366 & 0.645 \\
\hline GR & 0.750 & 0.355 & 0.066 & 0.291 & 0.156 & 0.383 \\
\hline $\mathrm{HU}$ & 0.750 & 0.322 & 0.120 & 0.476 & 0.151 & 0.464 \\
\hline IR & 0.750 & 0.409 & 0.130 & 0.363 & 0.260 & 0.425 \\
\hline IT & 0.750 & 0.372 & 0.116 & 0.346 & 0.139 & 0.359 \\
\hline $\mathrm{LU}$ & 0.750 & 0.413 & 0.131 & 0.374 & 0.345 & 0.533 \\
\hline NL & 0.750 & 0.467 & 0.168 & 0.397 & 0.283 & 0.472 \\
\hline PL & 0.750 & 0.328 & 0.099 & 0.301 & 0.093 & 0.295 \\
\hline $\mathrm{PT}$ & 0.750 & 0.371 & 0.083 & 0.303 & 0.216 & 0.625 \\
\hline SI & 0.750 & 0.355 & 0.077 & 0.317 & 0.154 & 0.425 \\
\hline $\mathrm{SP}$ & 0.750 & 0.408 & 0.091 & 0.277 & 0.147 & 0.283 \\
\hline SW & 0.750 & 0.400 & 0.162 & 0.420 & 0.456 & 0.685 \\
\hline UK & 0.750 & 0.388 & 0.133 & 0.352 & 0.260 & 0.441 \\
\hline $\mathrm{EU}$ & 0.750 & 0.378 & 0.133 & 0.378 & 0.260 & 0.482 \\
\hline EURO & 0.750 & 0.384 & 0.136 & 0.385 & 0.277 & 0.504 \\
\hline USA & 0.750 & 0.310 & 0.089 & 0.322 & 0.128 & 0.337 \\
\hline
\end{tabular}

Source: Own calculations based on EUROMOD and TAXSIM. Note: Bottom $75 \%$ of gross income distribution are assumed to be liquidity constrained. 
Figure 7: Income share of liquidity constrained households and government revenue

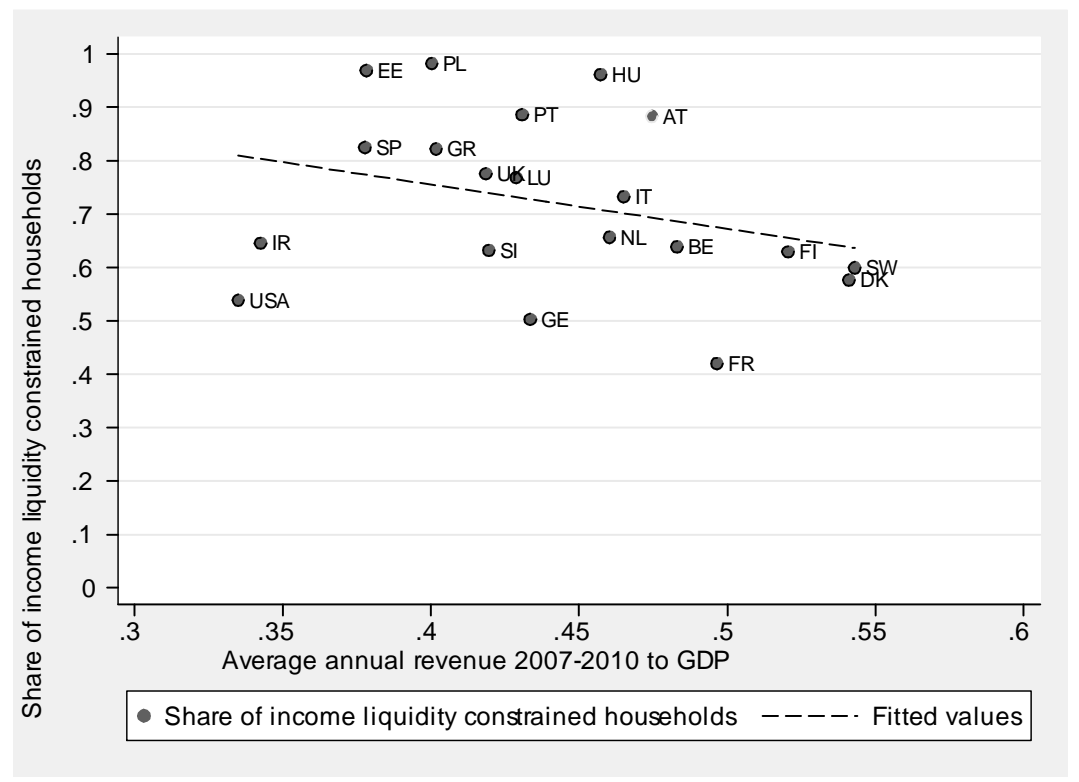

Source: Own calculations based on EUROMOD and TAXSIM, European Commission (2009a).

Figure 8: Discretionary measures and demand stabilization

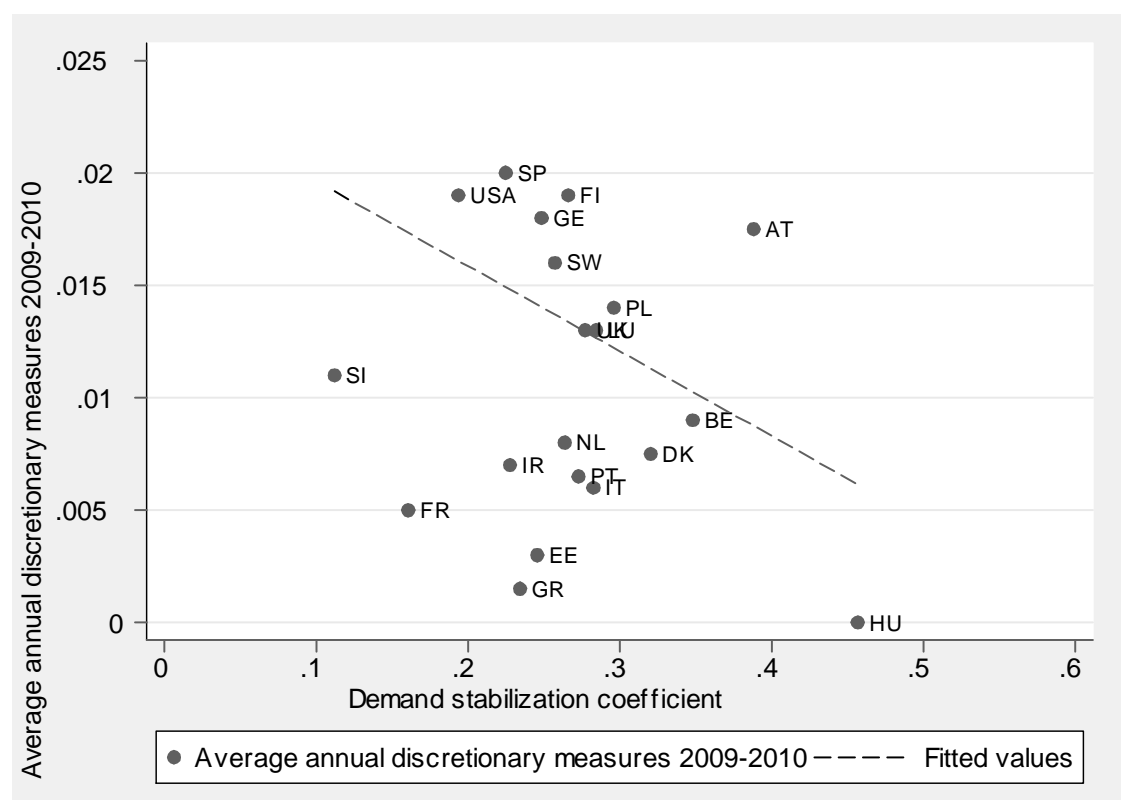

Source: Own calculations based on EUROMOD and TAXSIM, European Commission (2009c), IMF (2009). 
Figure 9: Discretionary measures and openness of the economy

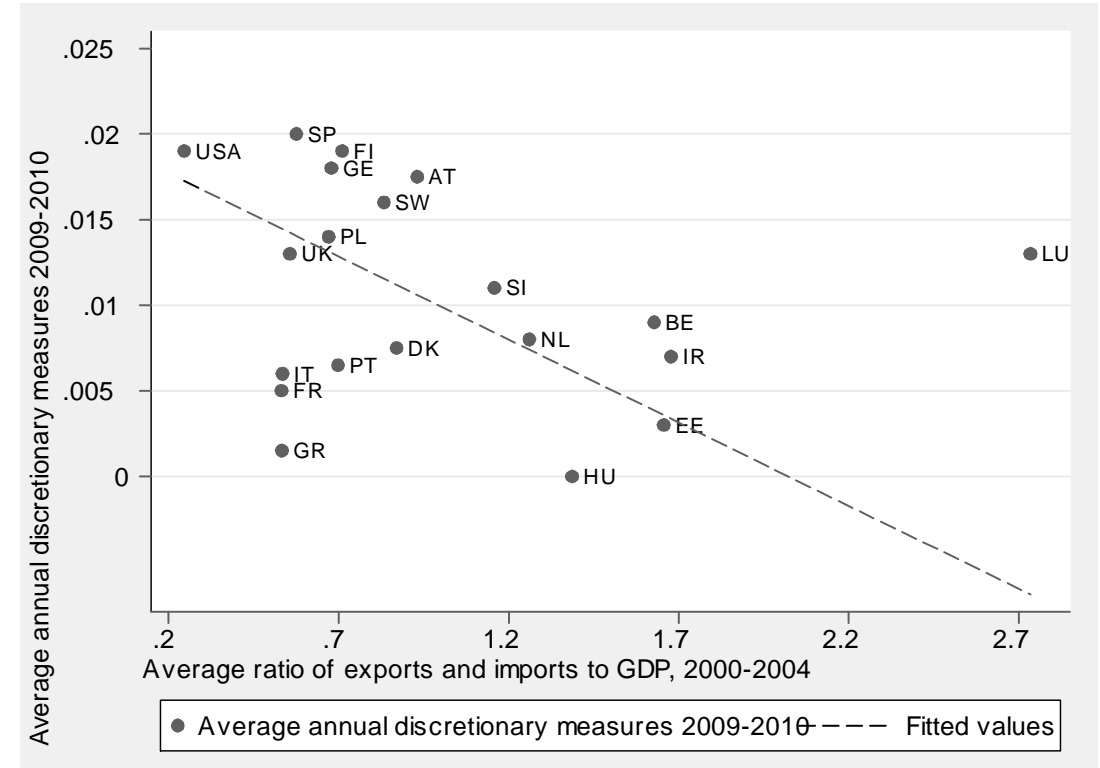

Source: Heston et al. (2006), European Commission (2009c), International Labour Office and International Institute for Labour Studies (2009) and IMF (2009). 


\section{A.2 Reweighting procedure for increasing unemployment}

In order to increase the unemployment rate while keeping the aggregate counts of other key individual and household characteristics constant, we follow the approach taken by Immvervoll et al. (2006). The increase of the unemployment rates is modeled through reweighting of our samples while controlling for several individual and household characteristics that determine the risk of becoming unemployed.

We follow Immvervoll et al. (2006) and define the unemployed as people aged 19-59 declaring themselves to be out of work and looking for a job. The withindatabase national 'unemployment rate' is calculated as the ratio of these unemployed to those in the labor force, defined as the unemployed plus people aged 19-59 who are (self)employed. The increased total number of unemployed people is calculated by adding 5 percentage points to the 'unemployment rate' within each country.

In EUROMOD, the baseline household weights supplied with the national databases have been calculated to adjust for sample design and/or differential nonresponse (see Sutherland (2001) for details). Weights are then recalculated using the existing weights as a starting point, but (a) using the increased (decreased) number of unemployed (employed) people as the control totals for them, and (b) also controlling for individual demographic and household composition variables using the existing grossed-up totals for these categories as control totals. The specific variables used as controls are:

- employment status

- age $(0-18,19-24,25-49,50-59,60+)$

- gender

- marital status and household size

- education

- region

This method implies that the households without any unemployed people that are similar to households with unemployed people (according to the above variables) will have their weights reduced. In other words, these are the households who are 'made unemployed' in our exercise. 


\section{References}

Aaberge, R., Björklund, A., Jäntti, M., Pedersen, P. J., Smith, N. and Wennemo, T. (2000). Unemployment Shocks and Income Distribution: How Did the Nordic Countries Fare during Their Crises?, Scandinavian Journal of Economics 102(1): 77-99.

Alesina, A. and Glaeser, E. (2004). Fighting Poverty in the U.S. and Europe: A World of Difference, Oxford University Press.

Alesina, A., Glaeser, E. and Sacerdote, B. (2005). Work and leisure in the U.S. and Europe: Why so different?, NBER Macroeconomcis Annual pp. 1-64.

Ankrom, J. (1993). An Analysis of Horizontal and Vertical Equity in Sweden, the U.S. and the U.K, Scandinavian Journal of Economics 95: 119-24.

Auerbach, A. (2009). Implementing the New Fiscal Policy Activism, American Economic Review: Papers and Proceedings 99:2: 543-549.

Auerbach, A. and Feenberg, D. (2000). The significance of federal taxes as automatic stabilizers, Journal of Economic Perspectives 14: 37-56.

Auerbach, A. and Hassett, K. (2002). Fiscal Policy and Uncertainty, International Finance 5: 229-249.

Bargain, O. (2006). Microsimulation in action: policy analysis in Europe using EUROMOD, vol. 25 of the series Research in Labor Economics, Elsevier.

Bayoumi, T. and Masson, P. (1995). Fiscal flows in the United States and Canada: Lessons for monetary union in Europe, European Economic Review 39: 253274 .

Bell, D. and Blanchflower, D. (2009). What Should Be Done about Rising Unemployment in the UK, IZA DP No. 4040.

Blanchard, O. (2006). Comments on 'The Case Against the Case Against Discretionary Policy', by Alan Blinder, in R. Kopcke, G. Tootell and R. Triest (eds), The macroeconomics of fiscal policy, MIT Press, Boston, pp. 62-67. 
Blanchard, O. and Perotti, R. (2002). An empirical characterization of the dynamic effects of changes in government spending and taxes on output, Quarterly Journal of Economics 117: 1329-1368.

Bourguignon, F. and Spadaro, A. (2006). Microsimulation as a tool for evaluating redistribution policies, Journal of Economic Inequality 4(1): 77-106.

Buettner, T. and Fuest, C. (2009). The Role of the Corporate Income Tax as an Automatic Stabilizer, Working Paper, Oxford University Centre for Business Taxation.

Cameron, D. (1978). The Expansion of the Public Economy: A Comparative Analysis, American Political Science Review 72: 1243-1261.

Devereux, M. and Fuest, C. (forthcoming). Is the Corporation Tax an Effective Automatic Stabilizer?, National Tax Journal .

Deville, J.-F. and Särndal, C.-E. (1992). Calibration estimators in survey sampling, Journal of the American Statistical Association 87: 376-382.

DiNardo, J., Fortin, N. and Lemieux, T. (1996). Labor Market Institutions and the Distribution of Wages, 1973-1992: A Semiparametric Approach, Econometrica 64: $1001-1044$.

Eaton, J. and Rosen, H. (1980). Optimal redistributive taxation and uncertainty, Quarterly Journal of Economics 95: 357-364.

European Commission (2009a). Public Finances in EMU 2009. 10th edition.

European Commission (2009b). Taxation trends in the European Union - 2009 edition.

European Commission (2009c). The EU's response to support the real economy during the economic crisis: an overview of Member States' recovery measures.

Fatàs, A. and Mihov, I. (2001). Government size and automatic stabilizers, Journal of International Economics 55: 3-28.

Feenberg, D. R. and Coutts, E. (1993). An Introduction to the TAXSIM Model,, Journal of Policy Analysis and Management 12(1): 189-194. 
Galí, J. (1994). Government size and macroeconomic stability, European Economic Review 38: 117-132.

Girouard, N. and André, C. (2005). Measuring cyclically-adjusted budget balances for OECD countries, OECD Economics Department Working Papers.

Goode, R. (1976). The Individual Income Tax, revised edition, Brookings., Washington.

Herault, N. (2009). Sequential Linking of Computable General Equilibrium and Microsimulation Models, WP No. 2/09, Melbourne Institute of Applied Economic and Social Research, The University of Melbourne.

Heston, A., Summers, R. and Aten, B. (2006). Penn World Table Version 6.2, Center for International Comparisons of Production, Income and Prices at the University of Pennsylvania.

IMF (2009). Group of Twenty - Global Economic Policies and Prospects, Note by the Staff of the International Monetary Fund.

Immervoll, H., Kleven, H., Kreiner, C. and Saez, E. (2007). Welfare Reform in European Countries: A Micro-Simulation Analysis, The Economic Journal 117 (516): 1-44.

Immvervoll, H. (2004). Average and marginal effective tax rates facing workers in the EU. A micro-level analysis of levels, distributions and driving factors, EUROMOD Working Paper Series.

Immvervoll, H., Levy, H., Lietz, C., Mantovani, D. and Sutherland, H. (2006). The sensitivity of poverty rates to macro-level changes in the European Union, Cambridge Journal of Economics 30: 181-199.

International Labour Office and International Institute for Labour Studies (2009). The financial and economic crisis: A decent work response.

Johnson, D., Parker, J. and Souleles, N. (2006). Household Expenditure and the Income Tax Rebates of 2001, American Economic Review 96(5): 1589-1610.

Kleven, H. J. and Kreiner, C. (2006). The Marginal Cost of Public Funds in OECD Countries: Hours of Work versus Labor Force Participation, Journal of Public Economics 90: 1955-1973. 
Mabbett, D. (2004). Fiscal Stabilisers In Europe: The Macroeconomic Impact Of Tax and Benefit Systems, EUROMOD Working Paper No. EM7/04.

Mabbett, D. and Schelkle, W. (2007). Bringing macroeconomics back into the political economy of reform: the Lisbon Agenda and the 'fiscal philosophy' of the EU, Journal of Common Market Studies 45: 81-104.

McIntyre, R. S., Denk, R., Francis, N., Gardner, M., Gomaa, W., Hsu, F. and Sims, R. (2003). Who pays? A Distributional Analysis of the Tax Systems in All 50 States, Institute on Taxation and Economic Policy.

Mélitz, J. and Zumer, F. (2002). Regional redistribution and stabilization by the central governement in canada; france; the uk and the us: A reassessment and new tests, Journal of Public Economics 86 (2): 263-286.

Parker, J. (1999). The Reaction of Household Consumption to Predictable Changes in Social Security Taxes, American Economic Review 89 (4): 959-973.

Pechman, J. (1973). Responsiveness of the Federal Income Tax to Changes in Income, Brookings Papers on Economic Activitiy 2: 385-421.

Pechman, J. (1987). Federal Tax Policy, Brookings, Washington.

Piketty, T. and Saez, E. (2007). How Progressive is the U.S. Federal Tax System? A Historical and International Perspective, Journal of Economic Perspectives 21 (1): 3-24.

Prescott, E. C. (2004). Why do Americans work so much more than Europeans?, Federal Reserve Bank of Minneapolis Quarterly Review 28 (1): 2-13.

Reinhart, C. and Rogoff, K. (2009). The Aftermath of Financial Crisis, American Economic Review: Papers $\&$ Proceedings 99 (2): 466-472.

Rodrik, D. (1998). Why Do More Open Economies Have Bigger Governments?, Journal of Political Economy 106: 997-1032.

Sachs, J. and Sala-i Martin, X. (1992). Fiscal Federalism and Optimum Currency Areas: Evidence for Europe from the United States, in M. B. Canzoneri, V. Grilli and P. R. Masson editors, "Establishing a Central Bank: Issues in Europe and Lessons from the U.S.", Cambridge University Press. 
Saez, E. (2001). Using elasticities to derive optimal income tax rates, Review of Economic Studies 68: 205-229.

Saez, E. (2002). Optimal income transfer programs: intensive versus extensive labor supply responses, Quarterly Journal of Economics 117: 1039-1073.

Shapiro, M. D. and Slemrod, J. (1995). Consumer response to the timing of income: Evidence from a change in tax withholding, American Economic Review 85(1): 274-283.

Shapiro, M. D. and Slemrod, J. (2003). Consumer response to tax rebates, American Economic Review 93(1): 381-396.

Shapiro, M. D. and Slemrod, J. (2009). Did the 2008 tax rebates stimulate spending?, American Economic Review: Papers $\&$ Proceedings 99(2): 374-379.

Souleles, N. (1999). The Response of Household Consumption to Income Tax Refunds, American Economic Review 89 (4): 947-958.

Sutherland, H. (2001). Final Report - EUROMOD: An Integrated European BenefitTax Model, EUROMOD Working Paper No. EM9/01.

Sutherland, H. (2007). Euromod: the tax-benefit microsimulation model for the European Union, in A. Gupta and A. Harding (eds), Modelling Our Future: Population Ageing, Health and Aged Care, Vol. 16 of International Symposia in Economic Theory and Econometrics, Elsevier, pp. 483-488.

van den Noord, P. (2000). The size and role of automatic stabilisers in the 1990s and beyond, OECD Economics Department Working Papers, No.230.

Zeldes, S. (1989). Consumption and Liquidity Constraints: An Empirical Investigation, Journal of Political Economy 97 (2): 305-346. 